Research Article

\title{
Finite Element Analysis of Thermal Effects in Diode End-Pumped Solid-State Lasers
}

\author{
Moustafa Sayem El-Daher ${ }^{1,2}$ \\ ${ }^{1}$ Physics Department, Damascus University, Damascus, Syria \\ ${ }^{2}$ Faculty of Informatics and Communications, Arab International University, Daraa, Syria \\ Correspondence should be addressed to Moustafa Sayem El-Daher; eldaherm@scs-net.org
}

Received 23 November 2016; Revised 6 February 2017; Accepted 2 March 2017; Published 10 April 2017

Academic Editor: Augusto Beléndez

Copyright (c) 2017 Moustafa Sayem El-Daher. This is an open access article distributed under the Creative Commons Attribution License, which permits unrestricted use, distribution, and reproduction in any medium, provided the original work is properly cited.

Thermal effects are the main obstacle to getting high power and good beam quality in diode end-pumped solid-state lasers. In this work, a theoretical investigation of thermal effects in single and dual end-pumped solid-state lasers is carried out using finite element analysis (FEA) for a selected number of widely used laser producing materials, namely, Nd:YAG, Yb:YAG, and Nd:KGW. Crystals with different dimensions are also investigated both in single and in dual end-pumped configuration. Finally, the effect of using composite crystals on thermal lensing is investigated. An experiment to measure the thermal focal length for two different crystals was carried out and a comparison with FEA computed focal length of the thermal lens is made. In all cases studied in this work, results show clear effects of thermal lensing with some differences depending on crystal type, pump power, and size.

\section{Introduction}

Obtaining high power output in diode pumped solid-state (DPSS) lasers with good beam quality is limited by the thermal effects in the laser crystal which induce thermal lensing and losses due to depolarization and cracks in the laser crystal [1-3].

For these purposes, a longitudinal pumping configuration was developed which is called end-pumped solid-state lasers which give high quality output beam and efficiency in comparison to side pumped lasers. For this goal, a fiber-coupled diode laser is used to pump the laser crystal longitudinally, and the end of the fiber is coupled to microlenses to adjust the pumping beam shape to match the mode $\mathrm{TEM}_{00}$ of the laser resonator to make use of all the output power of the diode laser [4]. Using fiber-coupled diode lasers provides a uniform pumping beam but the drawback is the focusing of high power on a small area of the face of the laser crystal which results in generating a large temperature gradient between the crystal center and the outside surface which gives thermal lens and stresses and birefringence [5]. In this work, we carried out FEA calculations for a selected number of laser producing crystals with different dimensions for a number of sizes and pumping parameters; we discussed the results and compared some of them to the actual experimental setup which gives us a better understanding of the numerical results and their deviation from the real measurement.

\section{Thermooptic Effects}

The difference between the energy of pumping photons and the energy of laser's photons in optically pumped solid lasers using diode lasers and quantum defects, which are called quantum defect heating, is the main reason for the heat generated in the crystal lattice of the lasing medium in addition to heat resulting from transfer of non-laser-emitting upper levels to ground levels [6].

The amount of heat generated inside the laser rod resulting from the absorption process of pumping light is dissipated by a heat sink on the surface of the laser rod cylindrical length; this is a condition of steady state assuming uniform internal heat generation. We can get such a setup using symmetrical pumping beam. End-pumping using a diode laser coupled with an optical fiber gives such beam distribution. Assume homogeneous cooling on the surface of the laser rod, which 
TABLE 1: Crystals studied in this work.

(a) Crystals studied using different pump power values

\begin{tabular}{llccr}
\hline & Crystal & Length $(\mathrm{mm})$ & Diameter $(\mathrm{mm})$ & Pump power \\
\hline 1 & Nd:YAG & 10 & 3 & 10,15, and $20 \mathrm{~W}$ \\
2 & Nd:YAG & 10 & 5 & 10,15, and $20 \mathrm{~W}$ \\
3 & Nd:YAG & 15 & 3 & 10,15 , and 20 W \\
4 & Nd:YAG & 15 & 5 & 10,15 , and 20 W \\
5 & Nd:KGW & 15 & 3 & 10,15 , and 20 W \\
6 & Nd:KGW & 15 & 5 & 10,15 , and 20 W \\
7 & Yb:YAG & 15 & 3 & 10,15 , and 20 W \\
8 & Yb:YAG & 15 & 5 & 10,15 , and 20 W \\
\hline
\end{tabular}

(b) Crystals studied using dual pump

\begin{tabular}{lcccc}
\hline & Crystal & Length $(\mathrm{mm})$ & Diameter $(\mathrm{mm})$ & Pump power \\
\hline 1 & Nd:YAG & 15 & 5 & 10 \\
2 & Nd:KGW & 15 & 5 & 10 \\
3 & Yb:YAG & 15 & 5 & 10 \\
\hline
\end{tabular}

(c) Composite crystals studied

\begin{tabular}{lcccc}
\hline & Crystal & Length $(\mathrm{mm})$ & Diameter $(\mathrm{mm})$ & Pump power \\
\hline 1 & Nd:YAG & 15 & 5 & 10 \\
2 & Nd:KGW & 15 & 5 & 10 \\
3 & Yb:YAG & 15 & 5 & 10 \\
4 & Nd: KGW & 15 & 5 & Dual pump 10 \\
\hline
\end{tabular}

means the temperature at each point along the axis of the crystal is fixed and the thermal conductivity coefficient $K_{c}$ is independent of temperature [7].

Under these assumptions, we can write a differential equation for thermal transfer in a cylindrical crystal as follows $[1,6-8]$ :

$$
\frac{1}{r} \frac{\partial}{\partial r}\left(r \frac{\partial T}{\partial r}\right)+\frac{\partial^{2} T}{\partial z^{2}}=-\frac{Q(r, z)}{K} .
$$

$T(r, z)$ is the temperature in kelvins as a function of radial distance $r$ and position along the $z$-axis, $K_{c}$ is the thermal conductivity $(\mathrm{W} / \mathrm{m} \cdot \mathrm{K})$, and $\mathrm{Q}(r, z)$ is heat in unit volume.

Thermal distribution within a laser crystal is a function of absorbed power density, which in turn takes the form of distributed light pumping at any vertical section on the axis of the laser crystal and parallel to the pumping beam. On the one hand, the intensity of light pumping decreases along the $z$ axis, subject to the law of absorption; $Q(r, z)$ can be given in a number of forms depending on the beam shape, for example, flat hat, top hat, Gaussian, or super Gaussian [9].

Boundary conditions are set based on the assumption that the side surface of the laser crystal is in direct contact with the heat radiator, generally made from a piece of copper in contact with a chiller. The first boundary condition is the continuity of thermal flow through these surfaces [7] and the second boundary condition is $T\left(r_{o}\right)=T_{c}$, where $T_{c}$ is the temperature set by the chiller.

The change in the refractive index can be separated into two terms: the first part depends on the temperature distribution and the second part depends on the strain [6]. So, we can write

$$
\mathbf{n}(r, z)=\mathbf{n}_{\mathbf{0}}+\Delta \mathbf{n}(r, z)_{\mathbf{T}}+\Delta \mathbf{n}(r, z)_{\boldsymbol{\varepsilon}},
$$

where $\mathbf{n}(r, z)$ is the total index of refraction, $\Delta \mathbf{n}(r, z)_{\mathrm{T}}$ is the part of index of refraction related to temperature, $\Delta \mathbf{n}(r, z)_{\boldsymbol{\varepsilon}}$ is the part of index of refraction related to stress, and $\mathbf{n}_{\mathbf{0}}$ is the material index of refraction.

\section{Theoretical Calculations and Results}

In this work, we carried out a finite element analysis study for three common types of solid-state laser crystals, namely, Nd:YAG (neodymium-doped yttrium aluminum garnet), $\mathrm{Nd}: \mathrm{Y}_{3} \mathrm{Al}_{5} \mathrm{O}_{12}, \mathrm{Yb}: \mathrm{YAG}$ (ytterbium-doped yttrium aluminum garnet), and $\mathrm{Nd}: \mathrm{KGW}$ (neodymium-doped potassiumgadolinium tungstate crystals $\left(\mathrm{Nd}: \mathrm{KGd}\left(\mathrm{WO}_{4}\right)_{2}\right)$. We studied thermal and stress properties within crystals choosing different dimensions for crystals and different pump power values as shown in Table 1(a).

We also explored dual pump configuration for the same crystals, for the three selected cases listed in Table 1(b); finally, we studied the effect of using a composite material on thermal effects in the selected crystals listed in Table 1(c).

In all calculations, LASCAD code [9] is used to implement thermal and structural finite element analysis (FEA). The method used depends on building a network of rectangular elements within the crystal connected to smaller irregular elements on the boundaries [10]. LASCAD code is used to calculate thermal and structural effects generated in 
TABLE 2: Parameters used in FEA calculations for crystals studied in this work.

\begin{tabular}{|c|c|c|c|}
\hline & Nd:YAG & $\mathrm{Nd}: K G W$ & Yb:YAG \\
\hline \multicolumn{4}{|l|}{ Thermal conductivity $\mathrm{W} / \mathrm{mm}^{\circ} \mathrm{K}$} \\
\hline$x$-component & 0.0103 & $2.8 \times 10^{-3}$ & 0.014 \\
\hline$y$-component & 0.0103 & $2.2 \times 10^{-3}$ & 0.014 \\
\hline$z$-component & 0.0103 & $3.5 \times 10^{-3}$ & 0.014 \\
\hline \multicolumn{4}{|l|}{ Coefficient of thermal expansion $1 /^{\circ} \mathrm{K}$} \\
\hline$x$-component & $4.0 \times 10^{-6}$ & $4.0 \times 10^{-3}$ & $7 \times 10^{-6}$ \\
\hline$y$-component & $4.0 \times 10^{-6}$ & $3.5 \times 10^{-3}$ & $7 \times 10^{-6}$ \\
\hline$z$-component & $4.0 \times 10^{-6}$ & $8.6 \times 10^{-3}$ & $7 \times 10^{-6}$ \\
\hline Refractive index & 1.823 & 2.033 & 1.82 \\
\hline Temperature dependence of refractive index $(d n / d T) 1 /{ }^{\circ} \mathrm{K}$ & $9.86 \times 10^{-6}$ & $4.0 \times 10^{-7}$ & $9 \times 10^{-6}$ \\
\hline Absorption coefficient (parallel polarization $\|$ ) & 0.35 & 3.5 & 0.3 \\
\hline Absorption coefficient (perpendicular polarization $\perp$ ) & 0.35 & 3.5 & 0.3 \\
\hline Heat efficiency factor & 0.3 & 0.3 & 0.11 \\
\hline Pump efficiency & 0.8 & 0.8 & 1 \\
\hline Stimulated emission cross section $\left(\mathrm{mm}^{2}\right)$ & $2.8 \times 10^{-17}$ & $3.8 \times 10^{-17}$ & $1.9 \times 10^{-18}$ \\
\hline Spontaneous lifetime $(\mu s)$ & 230 & 100 & 950 \\
\hline Pump laser spot size $(\mu \mathrm{m})$ & 300 & 300 & 300 \\
\hline
\end{tabular}
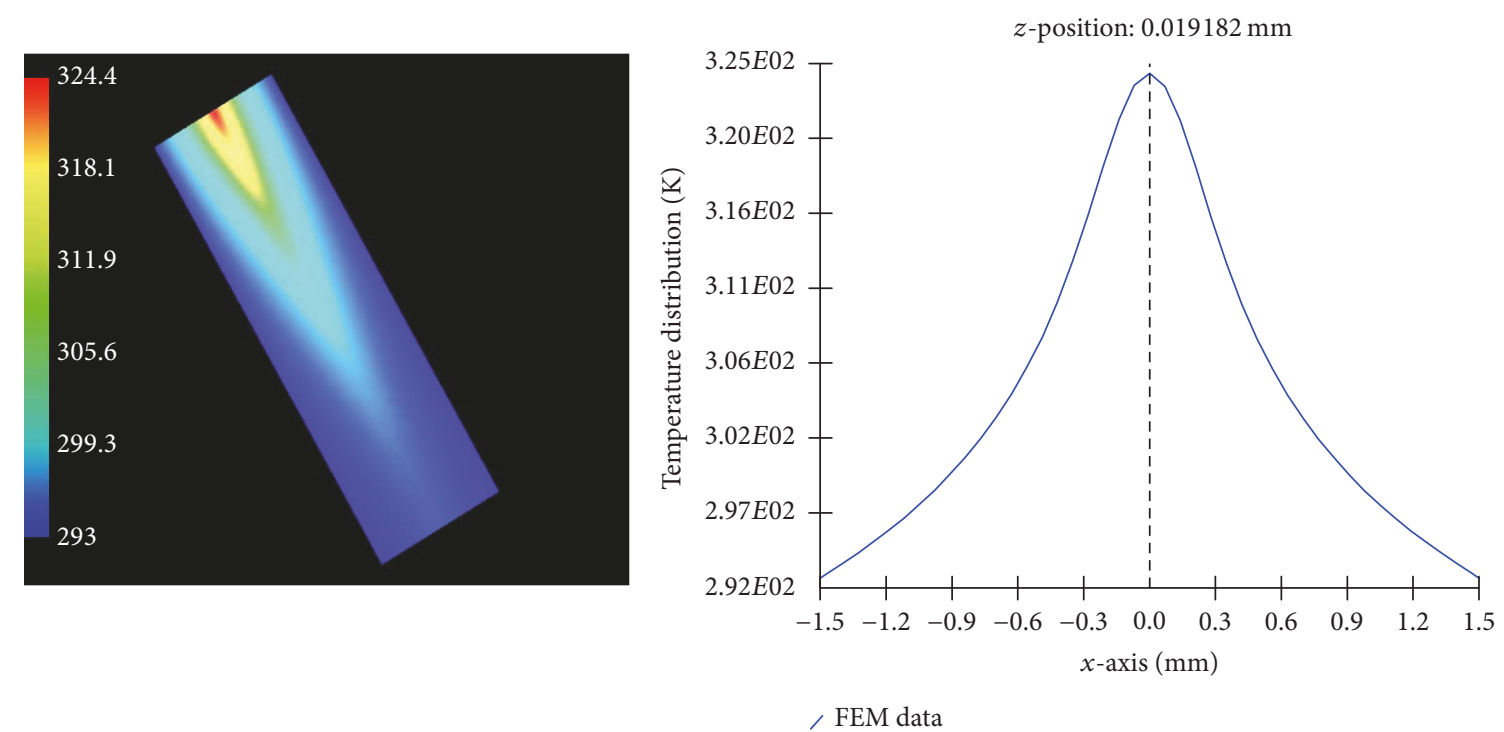

Figure 1: Temperature distribution for Nd:YAG with crystal length $10 \mathrm{~mm}$, radius $r=3 \mathrm{~mm}$, and pump power 10 watts. The same crystal with radius $r=5 \mathrm{~mm}$ and pump power 10 watts showed a similar temperature profile.

laser crystals. Finite element analysis is used to solve partial differential equations. The code allows the user to change dimensions of crystals, pump power, and beam profile in addition to many other parameters. The parameters used in this calculation and physical properties of the materials studied are listed in Table 2.

3.1. Temperature Distribution. In the end-pumped setup, the distribution of the temperature inside the laser crystal is a function of the absorbed power density, which in turn takes the shape of distributed light pumping at any vertical section on the axis of the crystal laser and parallel to the trend of pumping beam; on the one hand, the intensity of light pumping decreases along the $z$-axis and is subject to the law of absorption. The thermal gradient gives a gradual change in the index of refraction of the crystal and leads to the formation of a thermal lens.

In this work, we carried out finite element analysis to calculate the temperature distribution in crystals of different types with different dimensions, different pump power, and dual pump for some cases, as listed in Table 1. Results for temperature distribution for Nd:YAG crystal with different lengths and diameters are listed in Figures 1 and 2, and results for Nd:KGW are listed in Figure 3 and results for Yb:YAG are listed in Figure 4. All cases listed in Table 1 with different pump power values and diameters showed a similar 

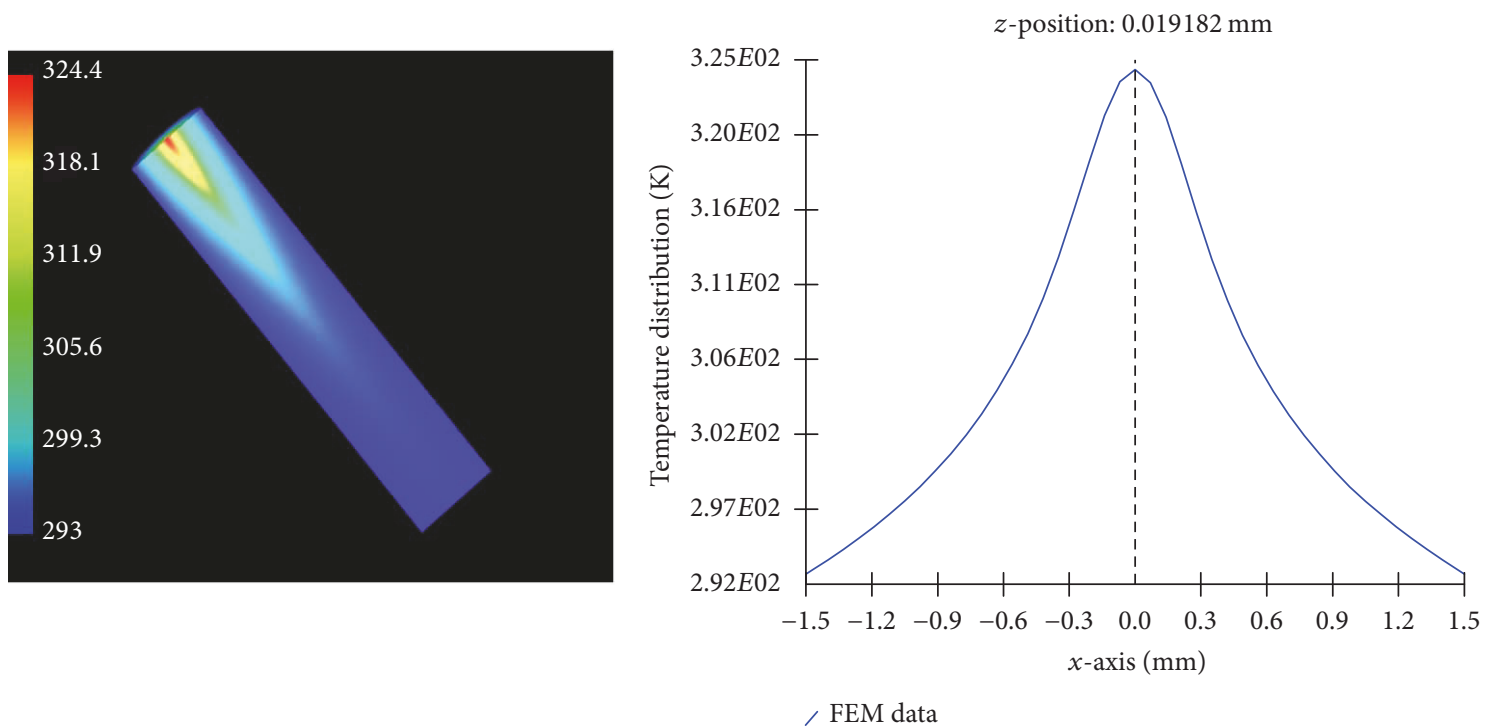

FIGURE 2: Temperature distribution for Nd:YAG with crystal length $15 \mathrm{~mm}$, radius $r=3 \mathrm{~mm}$, and pump power 10 watts. The same crystal with radius $r=5 \mathrm{~mm}$ and pump power 10 watts showed a similar temperature distribution profile.
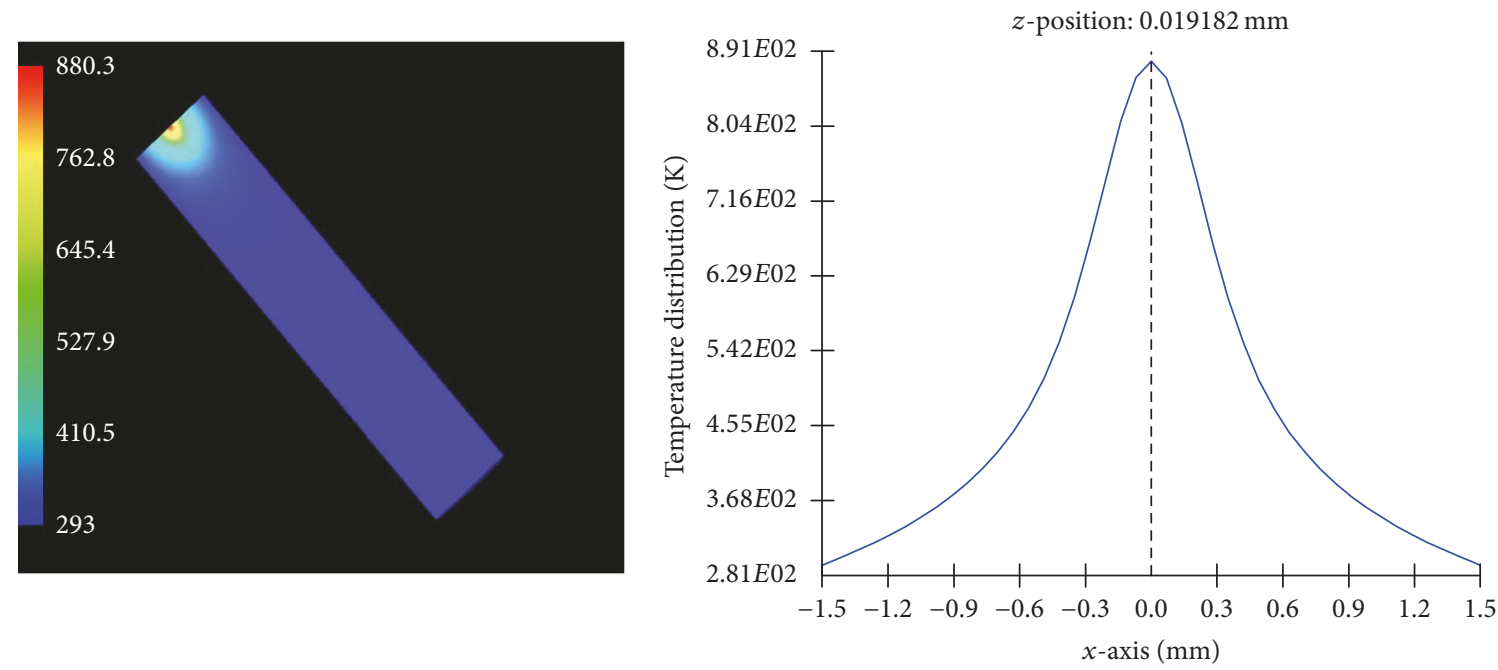

, FEM data

FIGURE 3: Temperature distribution for Nd:KGW with crystal length $15 \mathrm{~mm}$, radius $r=3 \mathrm{~mm}$, and pump power 10 watts. The same crystal with radius $r=5 \mathrm{~mm}$ and pump power 10 watts showed a similar temperature distribution profile.
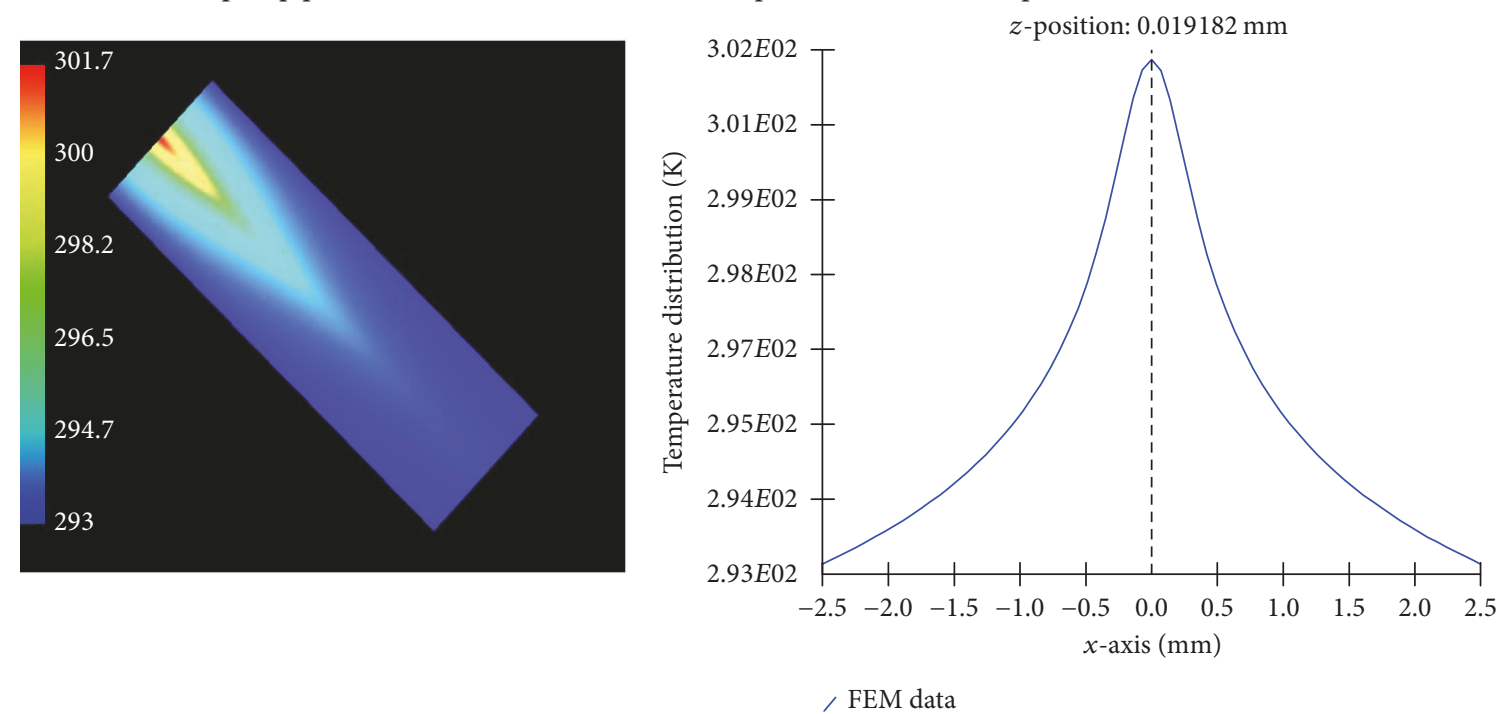

FIGURE 4: Temperature distribution for Yb:YAG with crystal length $15 \mathrm{~mm}$, radius $r=5 \mathrm{~mm}$, and pump power 10 watts. 


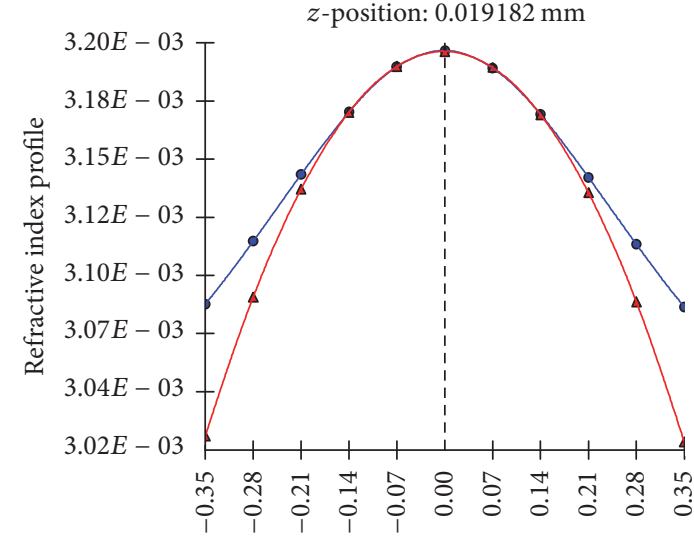

- FEM data

\ Parabolic fit

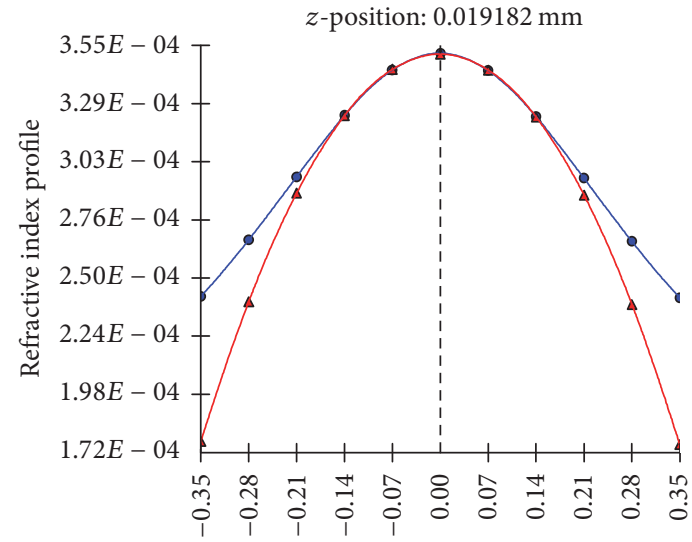

$x$-axis (mm)

- FEM data

\ Parabolic fit

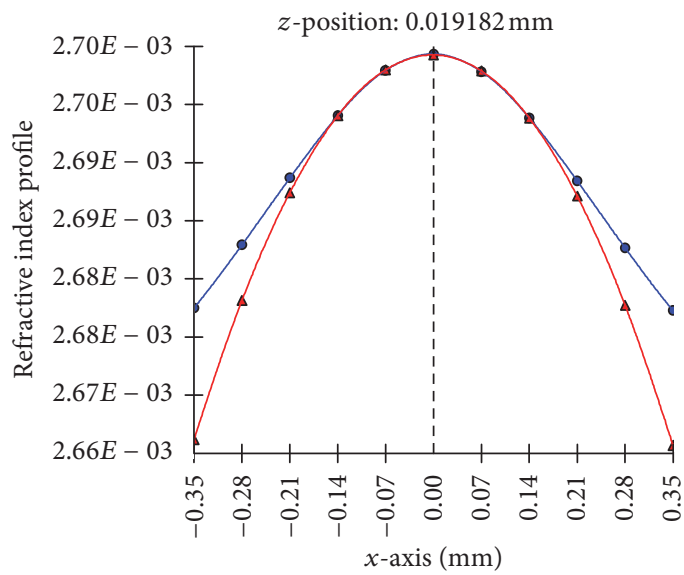

- FEM data

\ Parabolic fit

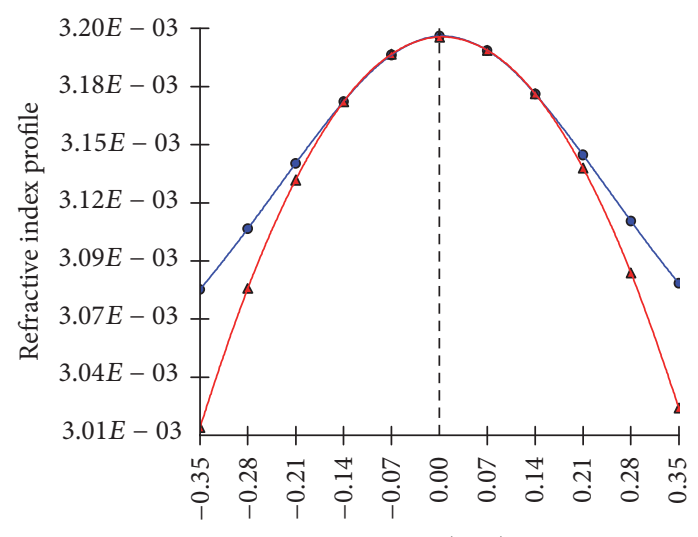

$y$-axis (mm)

- FEM data

\ Parabolic fit

(a)

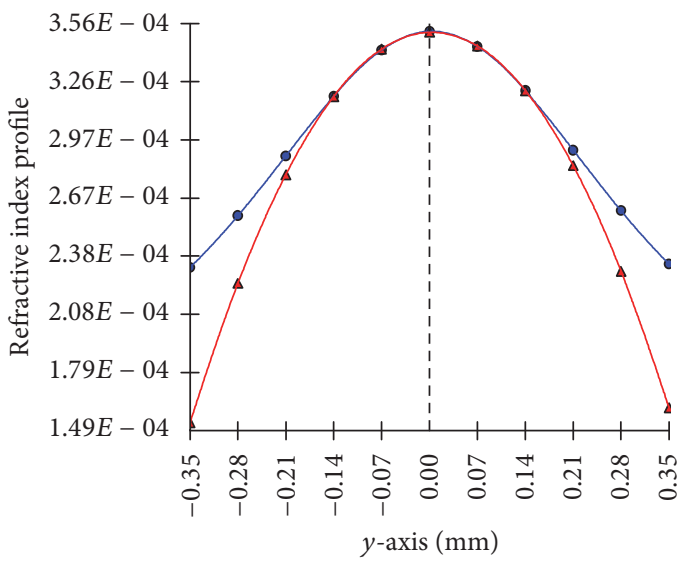

- FEM data

$\Delta$ Parabolic fit

(b)

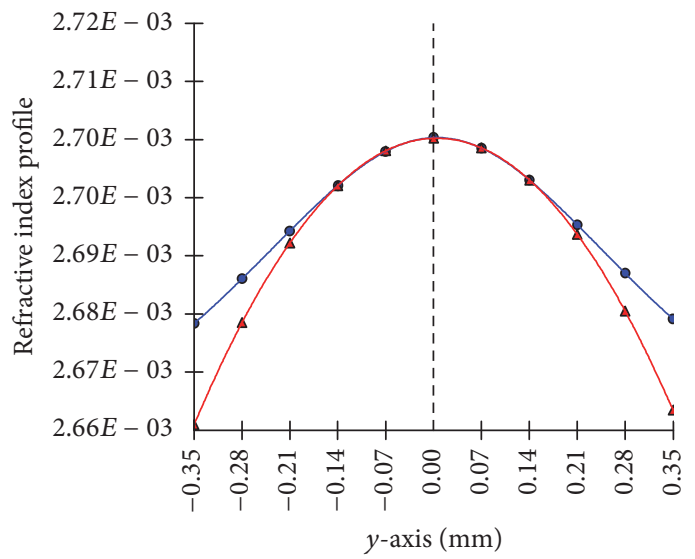

- FEM data

$\Delta$ Parabolic fit

(c)

FIGURE 5: Index of refraction profile obtained from FEA and parabolic fit for (a) Nd:YAG with length $10 \mathrm{~mm}$ and radius $r=3 \mathrm{~mm}$; (b) $\mathrm{Nd}$ :KGW with length $15 \mathrm{~mm}$ and radius $r=3 \mathrm{~mm}$; (c) Yb:YAG with length $15 \mathrm{~mm}$ and radius $r=3 \mathrm{~mm}$. Pump power is $10 \mathrm{~W}$ for all cases. 
TABLE 3: Maximum temperature within lasing crystal.

\begin{tabular}{lcccc}
\hline & Crystal & Length $(\mathrm{mm})$ & Diameter $(\mathrm{mm})$ & Maximum temperature, $T_{m}$ \\
\hline 1 & Nd:YAG & 10 & 3 & 324.4 \\
2 & Nd:YAG & 10 & 5 & 329.7 \\
3 & Nd:YAG & 15 & 3 & 324.4 \\
4 & Nd:YAG & 15 & 5 & 329.7 \\
5 & Nd:KGW & 15 & 5 & 917.2 \\
6 & Nd:KGW & 15 & 3 & 880.3 \\
7 & Yb:YAG & 15 & 5 & 301.7 \\
8 & Yb:YAG & 15 & 3 & 300.4 \\
\hline
\end{tabular}

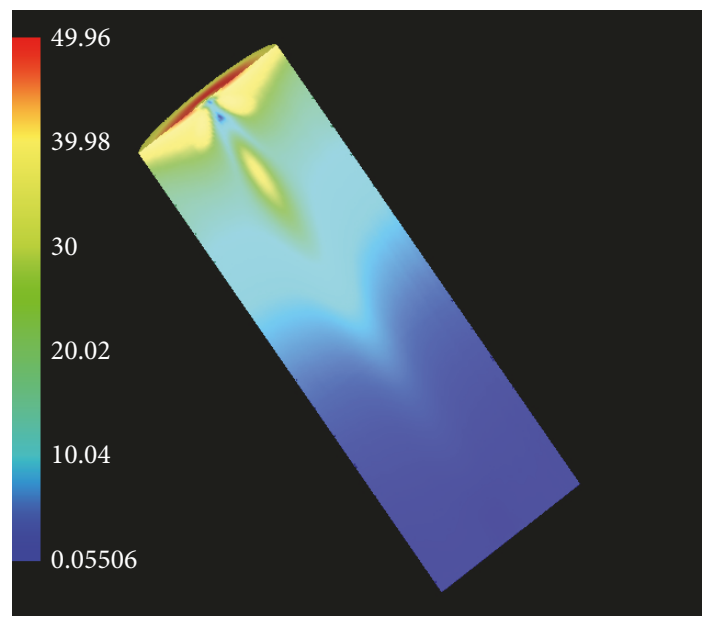

(a)

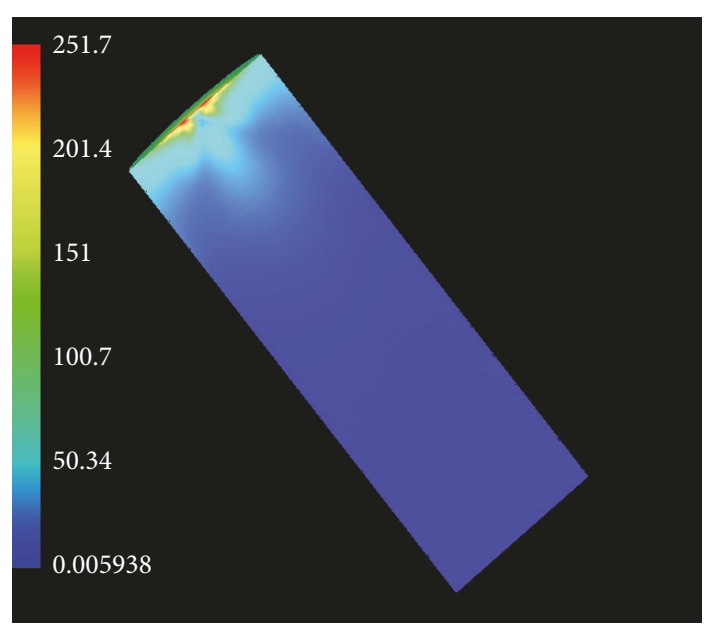

(c)

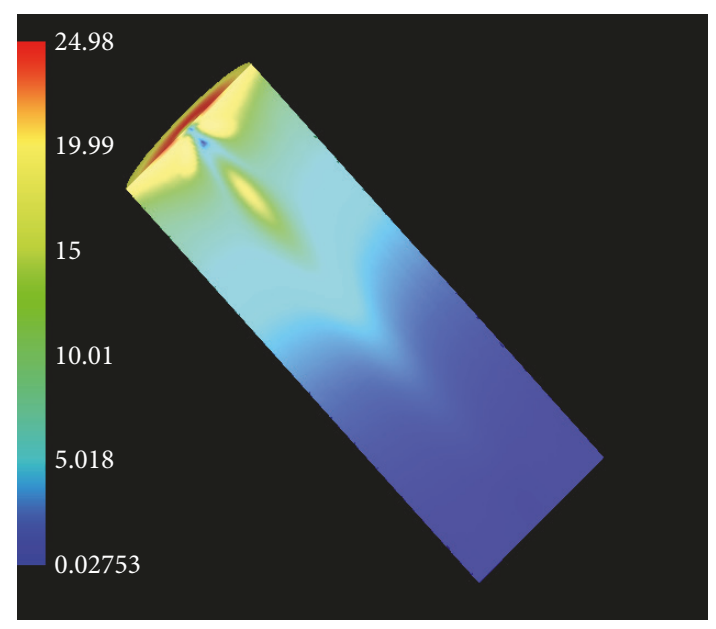

(b)

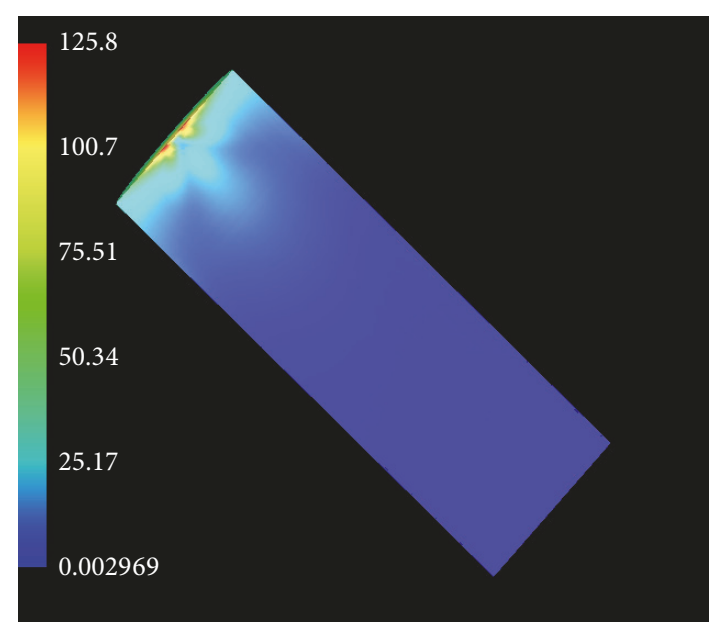

(d)

FIGURE 6: Stress intensity, N/mm². (a) Nd:YAG with crystal length $15 \mathrm{~mm}$, radius $r=5 \mathrm{~mm}$, and pump power 20 watts. (b) Nd:YAG with crystal length $15 \mathrm{~mm}$, radius $r=5 \mathrm{~mm}$, and pump power 10 watts. (c) Nd:KGW with crystal length $15 \mathrm{~mm}$, radius $r=3 \mathrm{~mm}$, and pump power 20 watts. (d) Nd:KGW with crystal length $15 \mathrm{~mm}$, radius $r=5 \mathrm{~mm}$, and pump power 10 watts.

temperature profile to those listed in Figures 1-4. We note that absorption length of $\mathrm{Nd}: \mathrm{KGW}$ crystal is much shorter than that of $\mathrm{Nd}: Y A G$ and $\mathrm{Yb}: \mathrm{YAG}$. The maximum temperature within crystals is listed in Table 3.

Figure 5 gives the index of refraction profile for selected crystals; other calculated values showed similar patterns.
3.2. Stress Distribution. The irregular distribution of heat also leads to the exposure of the crystal to mechanical stress. The outside surface temperature of the cylindrical laser crystal is fixed by a coolant and thus subject to contraction while the heat generated inside the crystal will cause its expansion; for this reason, interfaces areas are subject to mechanical 


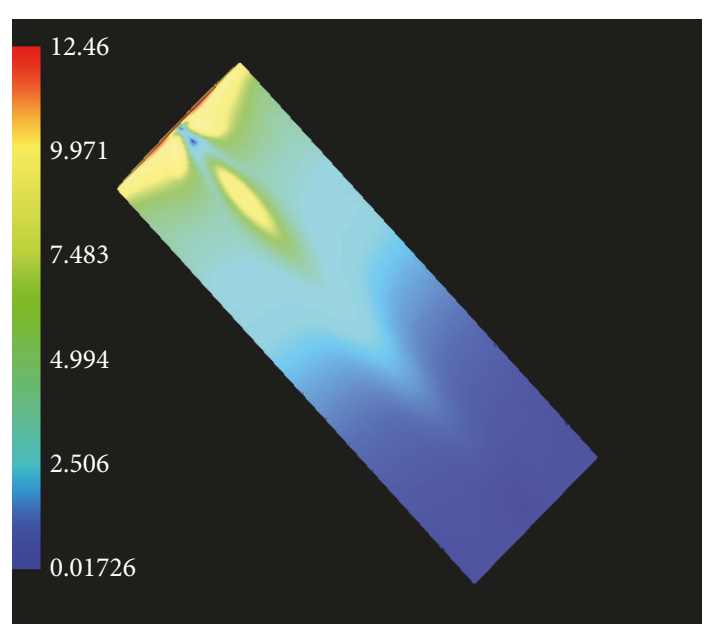

(a)

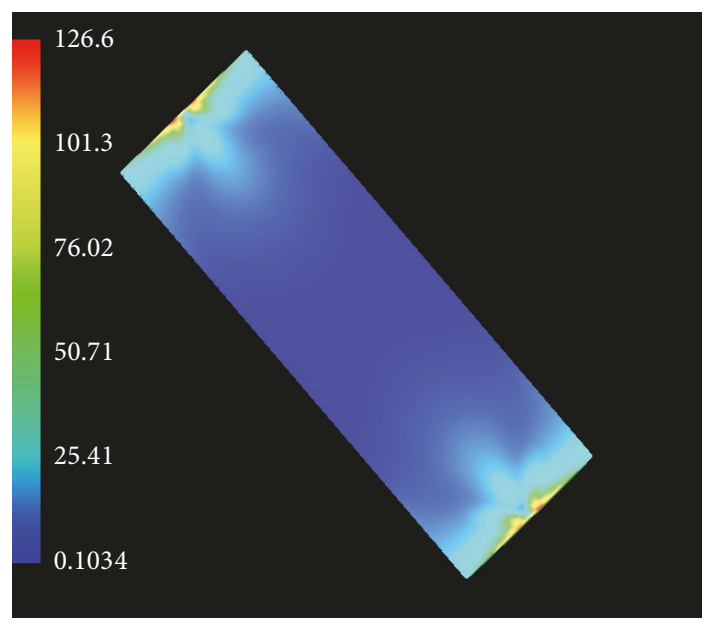

(c)

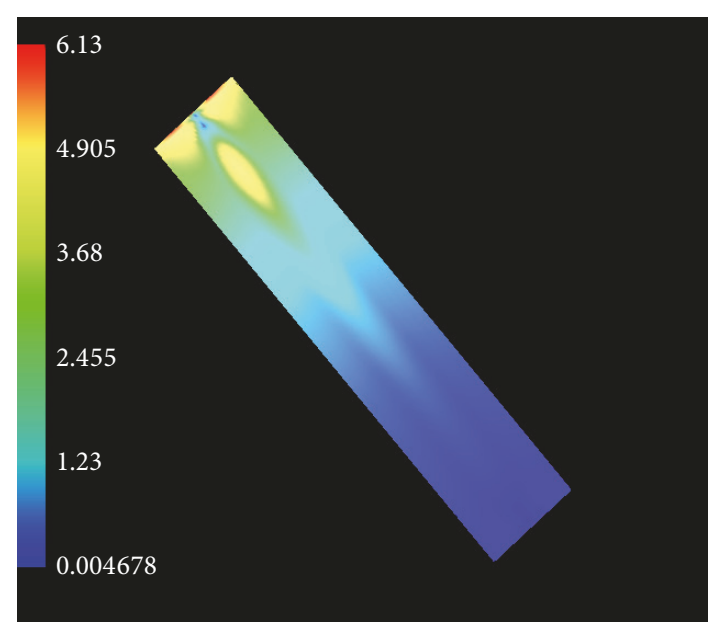

(b)

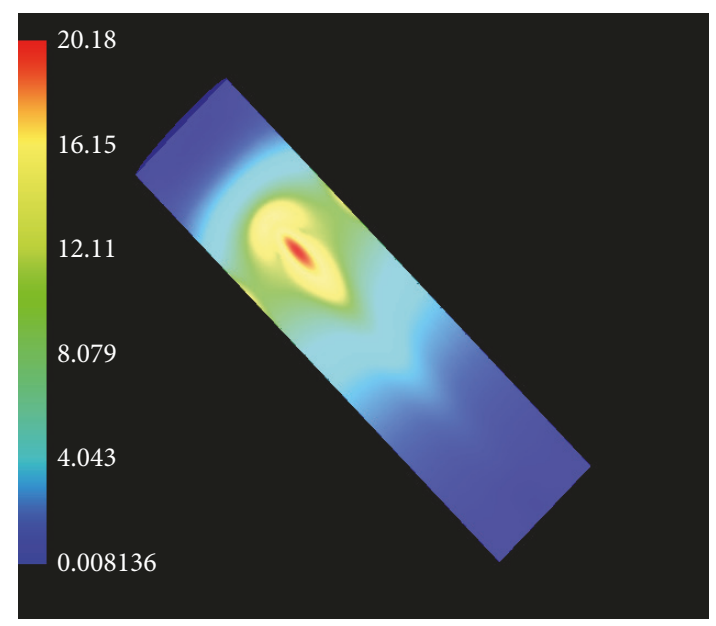

(d)

FIGURE 7: Stress intensity, N/mm². (a) Yb:YAG with crystal length $15 \mathrm{~mm}$, radius $r=5 \mathrm{~mm}$, and pump power 20 watts. (b) Yb:YAG with crystal length $15 \mathrm{~mm}$, radius $r=3 \mathrm{~mm}$, and pump power 10 watts. (c) Nd:KGW with crystal length $15 \mathrm{~mm}$, radius $r=3 \mathrm{~mm}$, and dual pump power 10 watts. (d) Nd:KGW composite with crystal length $15 \mathrm{~mm}$, radius $r=5 \mathrm{~mm}$, and pump power 10 watts and undoped cap of $5 \mathrm{~mm}$.

stresses that result in the creation of nonhomogeneity and the emergence of double refraction which produces loss due to polarization and a thermal lens is formed. Results of stress intensity in $\mathrm{N} / \mathrm{mm}^{2}$ are listed in Figures 6 and 7 for selected cases. We note that the stress is maximum around the area with the maximum temperature in all cases studied.

We note that stress values remained within a safe distance from the stress fracture point [4] for all cases studied except for ND:KGW crystal pumped with 20 watts. Stress distribution deserved a more detailed theoretical and experimental study, probably taking into account any mechanical stress resulting from mounting and fastening of the crystal in the casing.

3.3. Crystal Size and Pump Power. We calculated temperature distribution for crystals listed in Table 1(b), with results listed in Figures 8, 9, and 10. From the results listed in Table 3 and Figures $8-10$, we see that crystal size does not significantly affect the temperature drop and its effect on the maximum temperature $\left(T_{\max }\right)$ is less than $10 \%$ for the cases studied.

We note from Table 3 an increased absolute temperature of the center for the crystal of about of 6 degrees, when the radius of the crystal is increased by $2 \mathrm{~mm}$ for Nd:YAG, and 38 degrees in case of $\mathrm{Nd}$ :KGW.

For practical reasons, we cannot reduce the absolute temperature using smaller crystals because the crystal is small to begin with and it is very difficult in practice to cut and refine crystals of radius less than $2 \mathrm{~mm}$ and thus it can be concluded that the cross section of the crystal is not a parameter which can be changed effectively.

From the calculated results, we see that temperature within lasing crystals scaled linearly with pumping power.

We also investigated dual pump configuration for cases listed in Table 1(b), with results of temperature distribution and stress intensity listed in Figure 11. We note that the maximum temperatures are close to those of single pump 


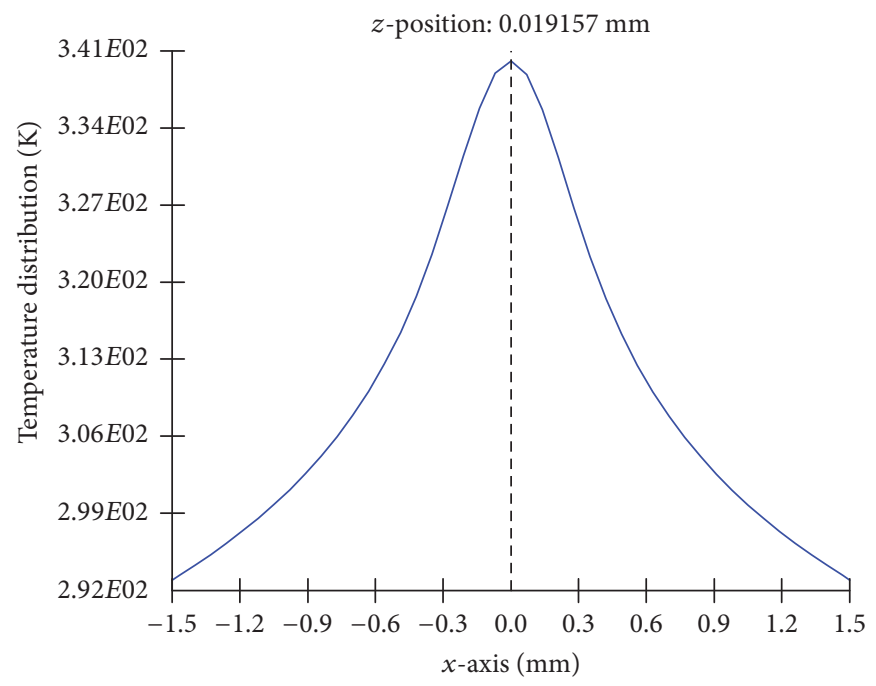

FEM data

(a)

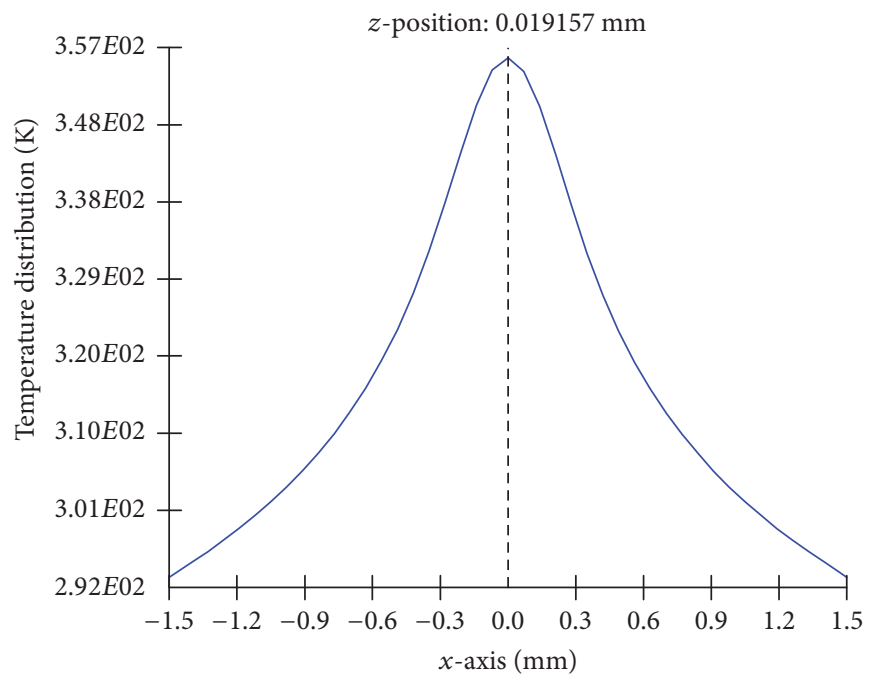

, FEM data

(b)

Figure 8: Temperature profile for Nd:YAG with crystal length $10 \mathrm{~mm}$ and radius $r=3 \mathrm{~mm}$. (a) Pump power 15 watts. (b) Pump power 20 watts.

configuration but duplicated at both ends which will create higher stress and thermal gradient within the crystal. We also note that the two separated absorption zones shown for all three cases in Figure 11 will result in significant depolarization in the crystal and it would be best to adjust the pump wavelength and rod length to the absorption profile with the minimum longitudinal variation.

3.4. Composite Crystal. Great thermal gradient appears near crystal surface in longitudinally pumped systems; this in turn causes the formation of thermal lenses and causes light deflection.
We can reduce the temperature gradient within the crystal by using composite crystals which have undoped caps which play the role of coolers at the two ends of the laser crystals and help in heat dissipation without abstracting the optical path.

From Figures 12, 13, and 14, we can see that numerical calculations showed that the maximum temperature of the center for a crystal in a $3 \mathrm{~mm}$ diameter Nd: KGW pumped with energy $10 \mathrm{~W}$ laser is up to about $880 \mathrm{~K}$ which can be reduced to about $600 \mathrm{~K}$ by adding crystals KGW with the same diameter and length of $3 \mathrm{~mm}$. The undoped part of the crystal does not contain thermal sources and contributes to 


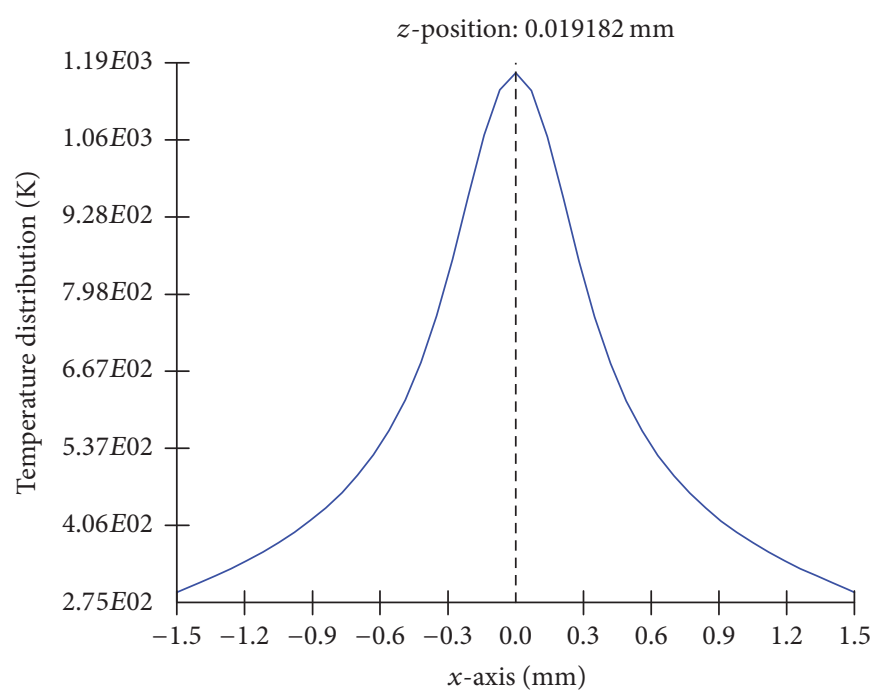

, FEM data

(a)

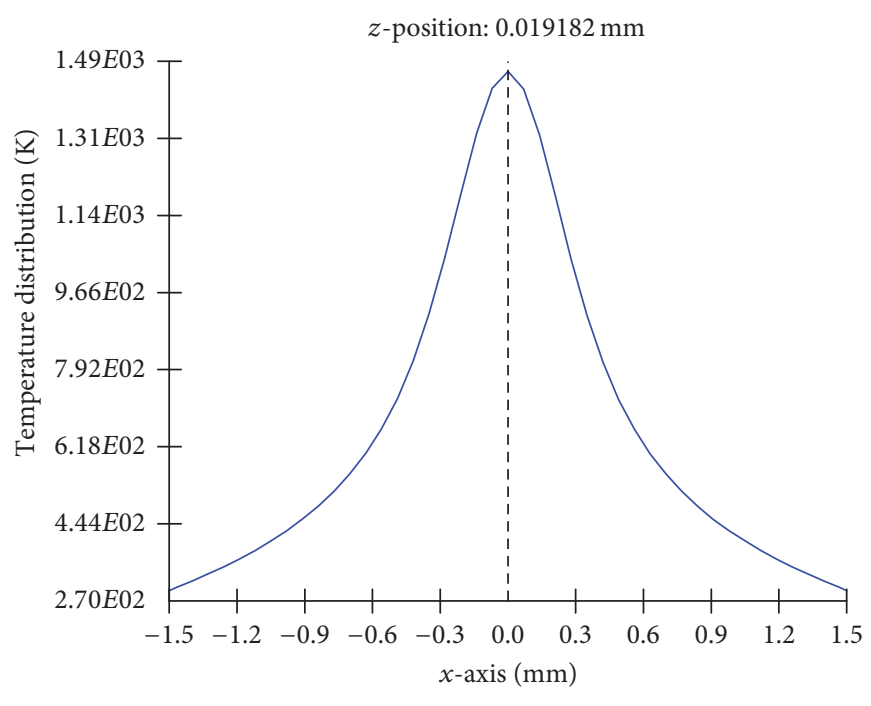

/ FEM data

(b)

Figure 9: Temperature profile for Nd:KGW with crystal length $15 \mathrm{~mm}$ and radius $r=3 \mathrm{~mm}$. (a) Pump power 15 watts. (b) Pump power 20 watts.

the transfer of heat to crystal faces pumped laser. Reduction of heat within Nd:YAG and Yb:YAG was not as big as Nd:KGW.

\section{Experimental Measurement of Thermal Lens}

In order to measure thermal effects, we used the following diode laser to pump some of the crystals studied theoretically and compare the experimental results to FEA predicted values.

The diode lasers used for pumping have an optical aperture of $400 \mu \mathrm{m}$ and $600 \mu \mathrm{m}$, with an SMA connector, variable output power up to $30 \mathrm{~W}$, and wavelength of $808 \mathrm{~nm}$ $( \pm 3 \mathrm{~nm})$, where the wavelength can be changed by changing the diode laser temperature. After exiting the optical fiber, the laser beam goes through a collimating and focusing optic fiber to reach the lasing crystal surface.

One method of measuring thermal lens is the geometrical method based on beam focusing; the idea of this method depends on passing helium-neon laser beam through a laser crystal during the pumping process; the optical path of the helium-neon laser beam does not show any change in the absence of pumping while suffering from the impact of the thermal lens with an increase in pumping power.

As can be seen in Figure 15 when starting the optical pumping of the laser crystal, the helium-neon laser beam converges as a result of the thermal lens within the crystal Nd: KGW as a result of pumping. 


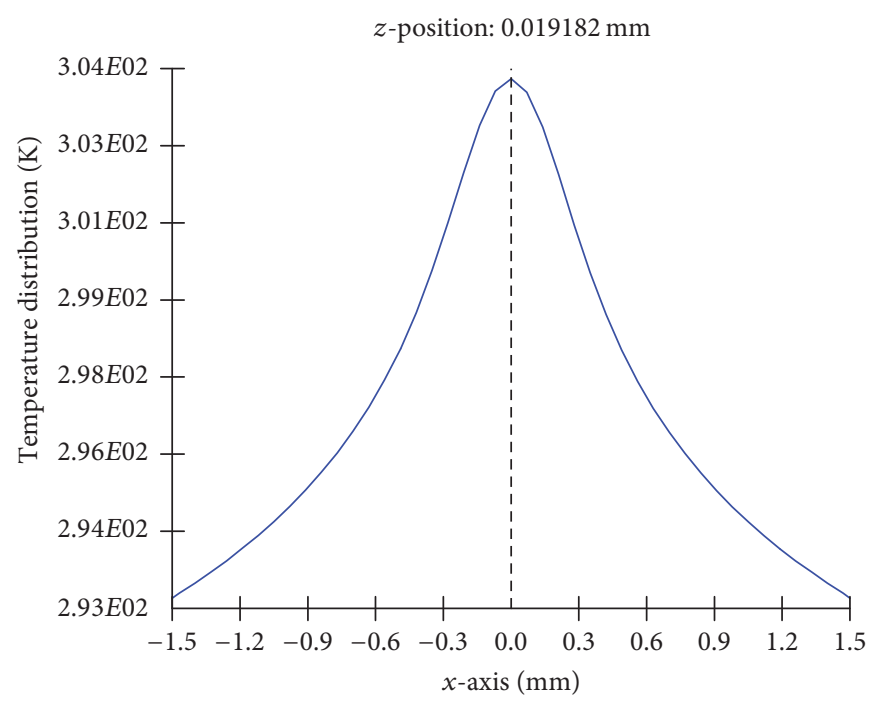

, FEM data

(a)

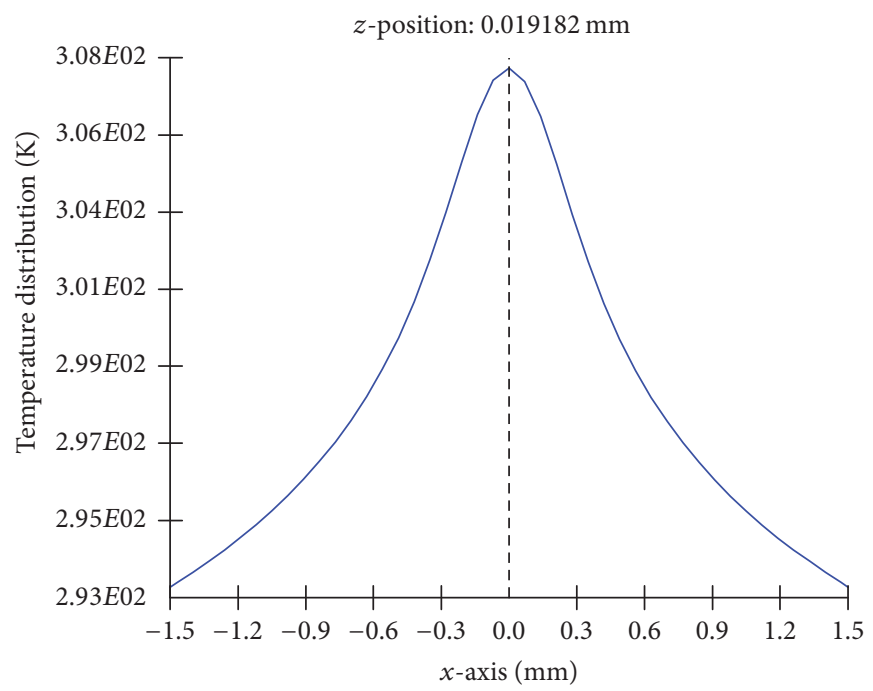

, FEM data

(b)

Figure 10: Temperature profile for Yb:YAG with crystal length $10 \mathrm{~mm}$ and radius $r=3 \mathrm{~mm}$. (a) Pump power 15 watts. (b) Pump power 20 watts.

By adjusting the CCD camera position, we can locate the position of the focal point of the helium-neon laser beam and we can measure the focal length of the thermal lens. Table 4 shows the thermal focal length calculated using FEA for selected cases.

Following the method mentioned above, we found that the focal length formed by the thermal lens in Nd:KGW crystal formed at pump power of $10 \mathrm{~W}$ is $138 \mathrm{~mm}$ from the face of the crystal. Comparing this result with the theoretical value of $154 \mathrm{~mm}$ calculated using FEA, we find that the measured value is $10 \%$ stronger than the predicted value; in our opinion, this is probably due to the fact that the heat source was concentrated in the center of the rod and there could have been heating in addition to quantum defect heating.

Under the same conditions, we found that the lens formed in Nd:KGW crystal has stronger thermal focus than the lens formed within the Nd:YAG crystal. This is because Nd:KGW has much higher absorption resulting in a substantially reduced cooling area and that is why the end cap on the composite rod improved KGW performance.

\section{Conclusions}

FEA analysis gives excellent quantitative prediction for heat and stress distribution within laser crystals and for predicting 

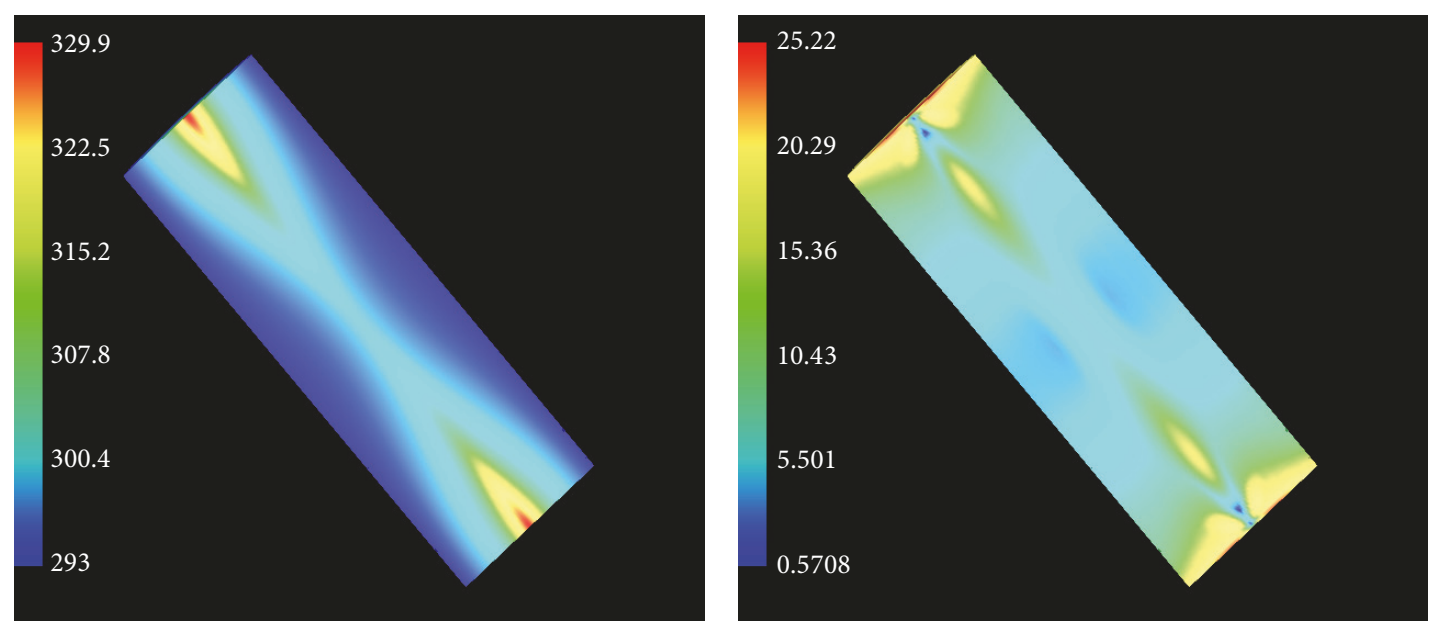

(a)
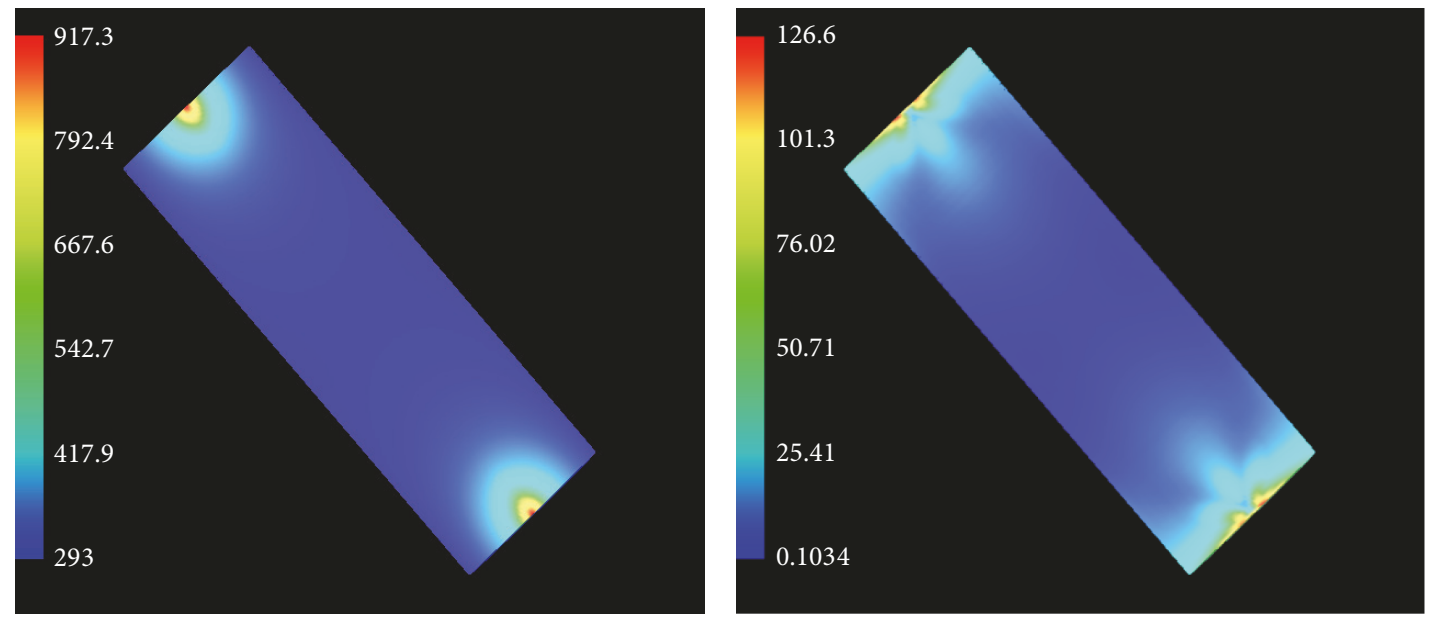

(b)
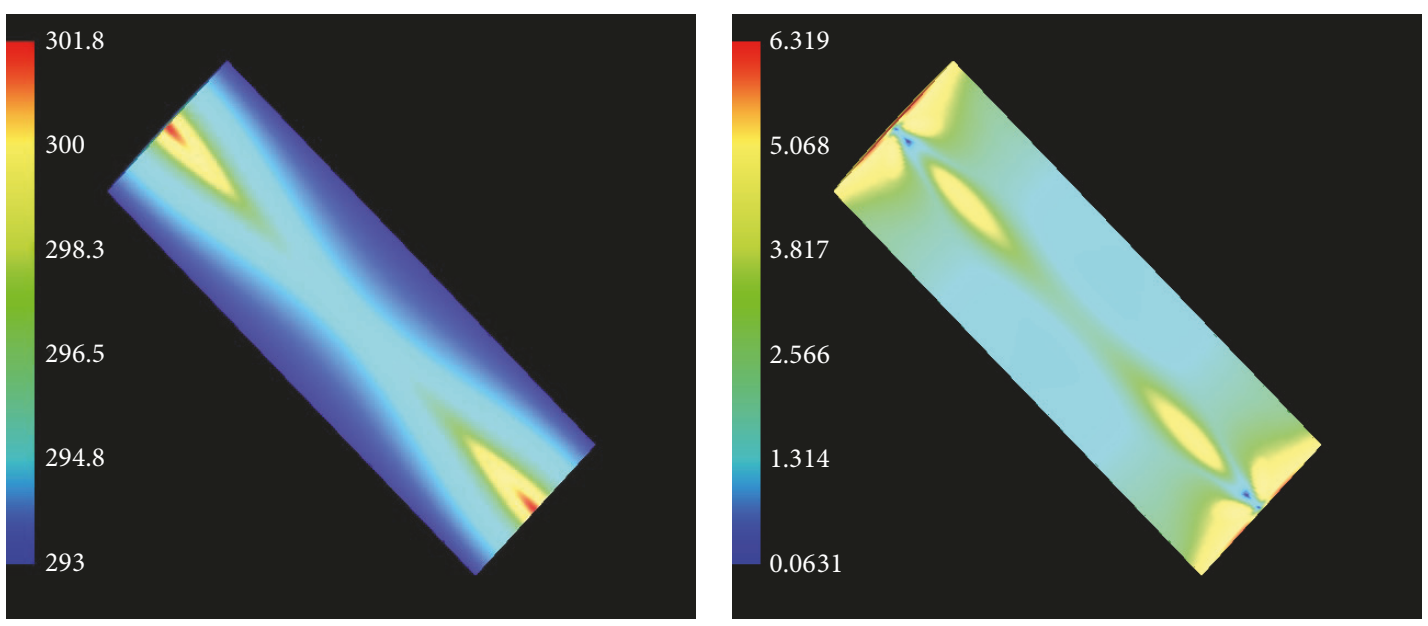

(c)

Figure 11: Temperature (left) and stress distribution (right) for dual pump configuration: (a) Nd:YAG, (b) Nd:KGW, and (c) Yb:YAG. 

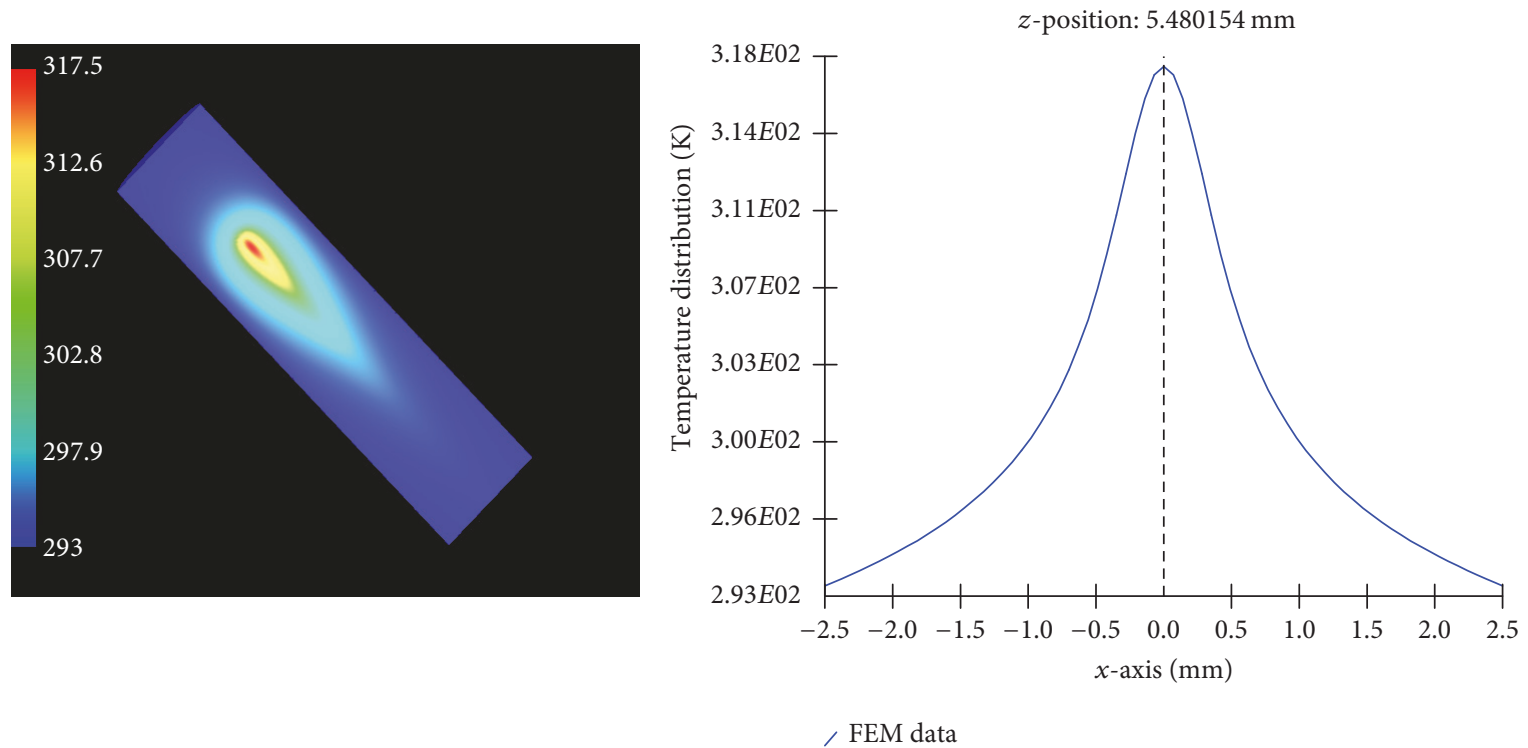

(a)
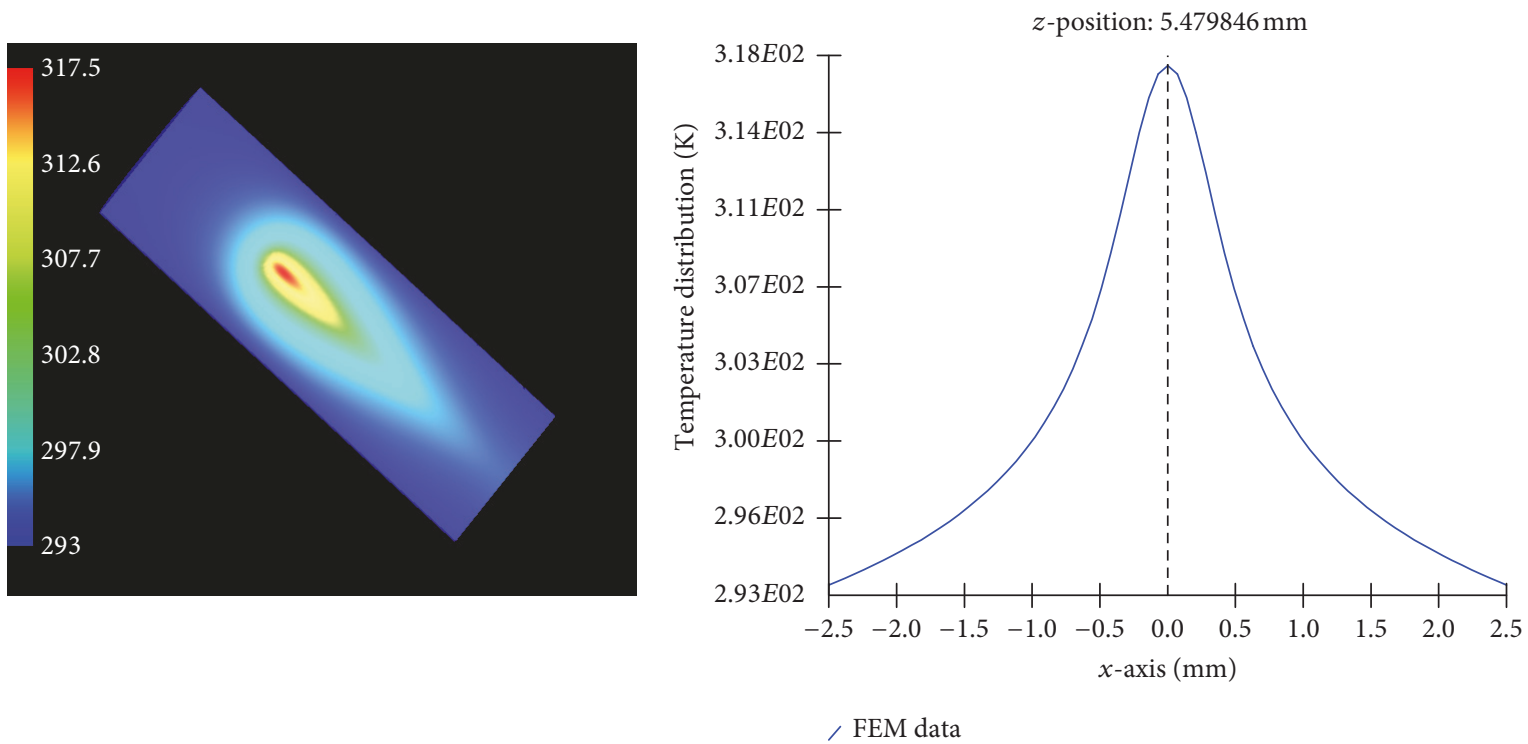

(b)

FigURE 12: Composite material Nd:YAG: (a) $15 \mathrm{~mm}$ and (b) $10 \mathrm{~mm}$, with radius $r=5 \mathrm{~mm}$ in both cases.
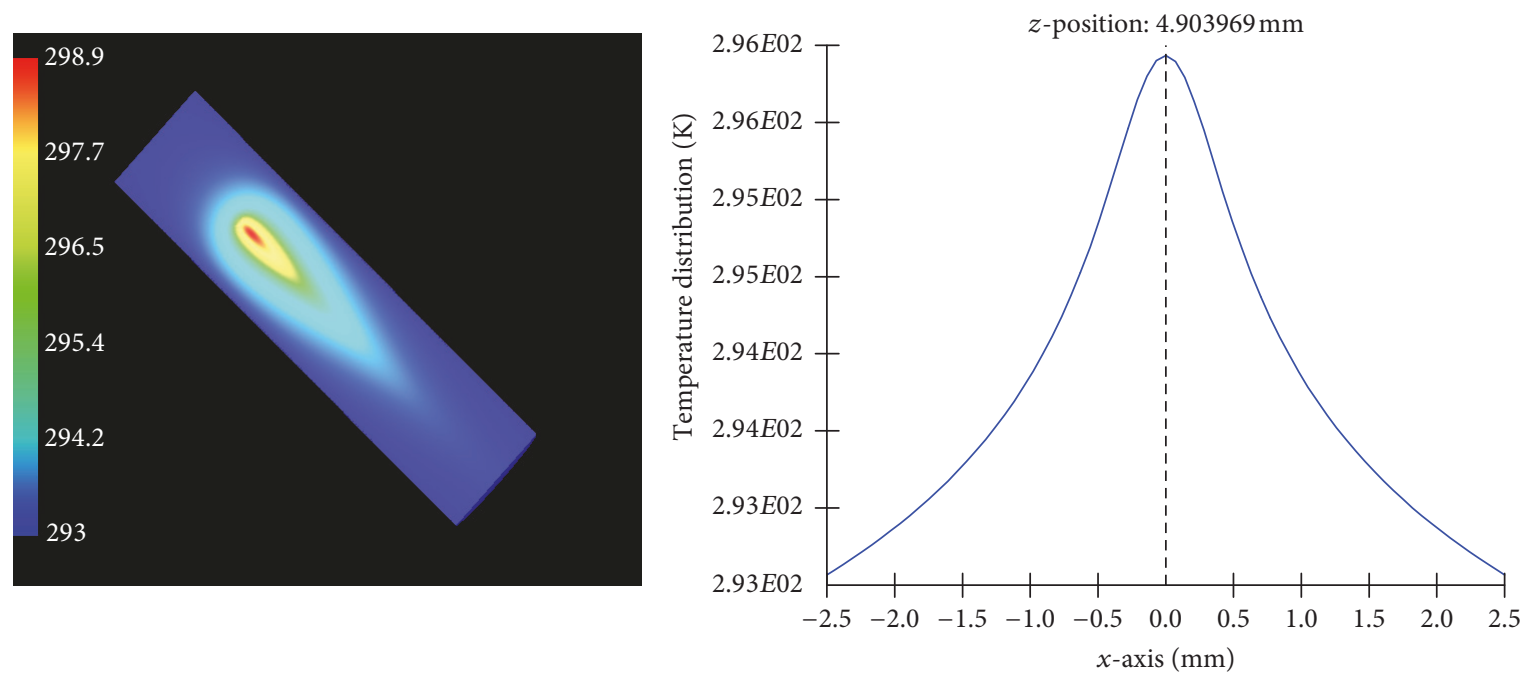

, FEM data

FIgURE 13: Composite material Yb:YAG: $15 \mathrm{~mm}$, radius $r=5 \mathrm{~mm}$, and a $5 \mathrm{~mm}$ undoped cap. 

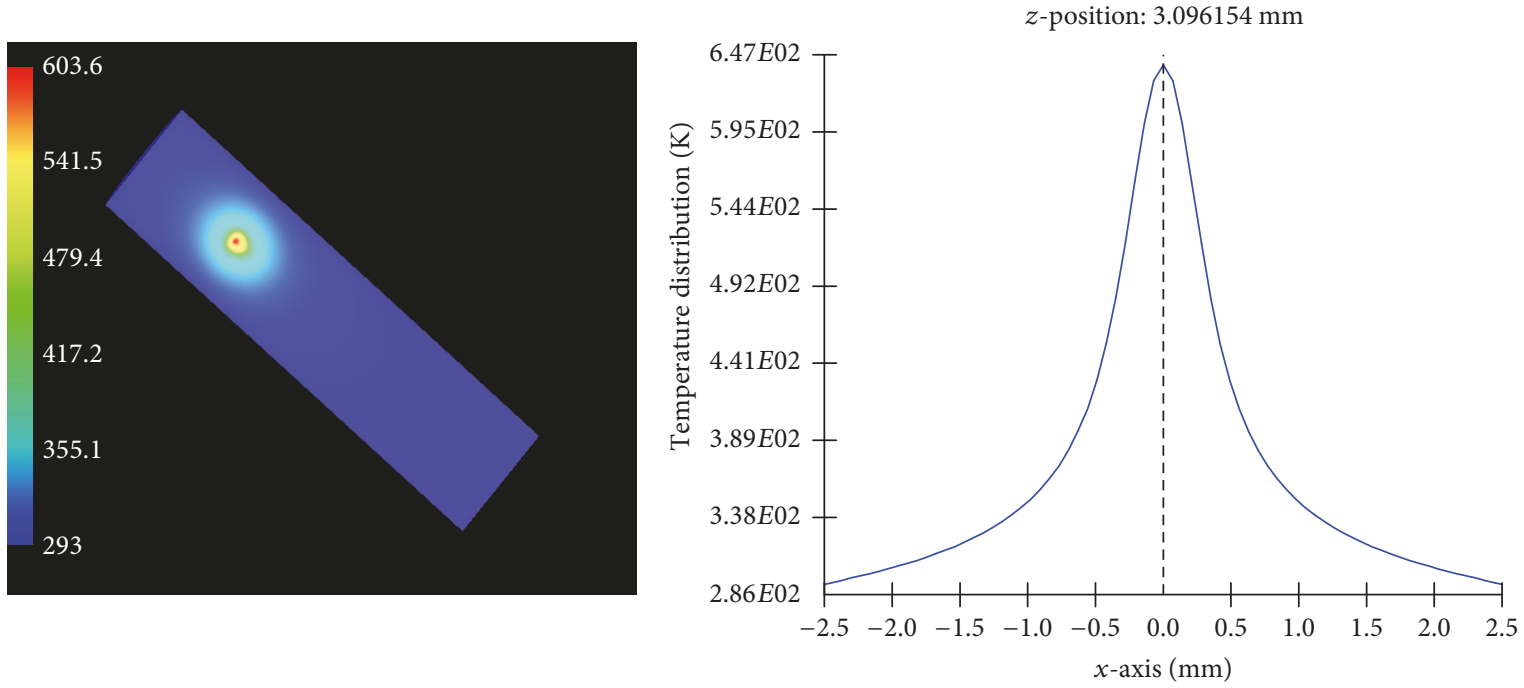

, FEM data

(a)
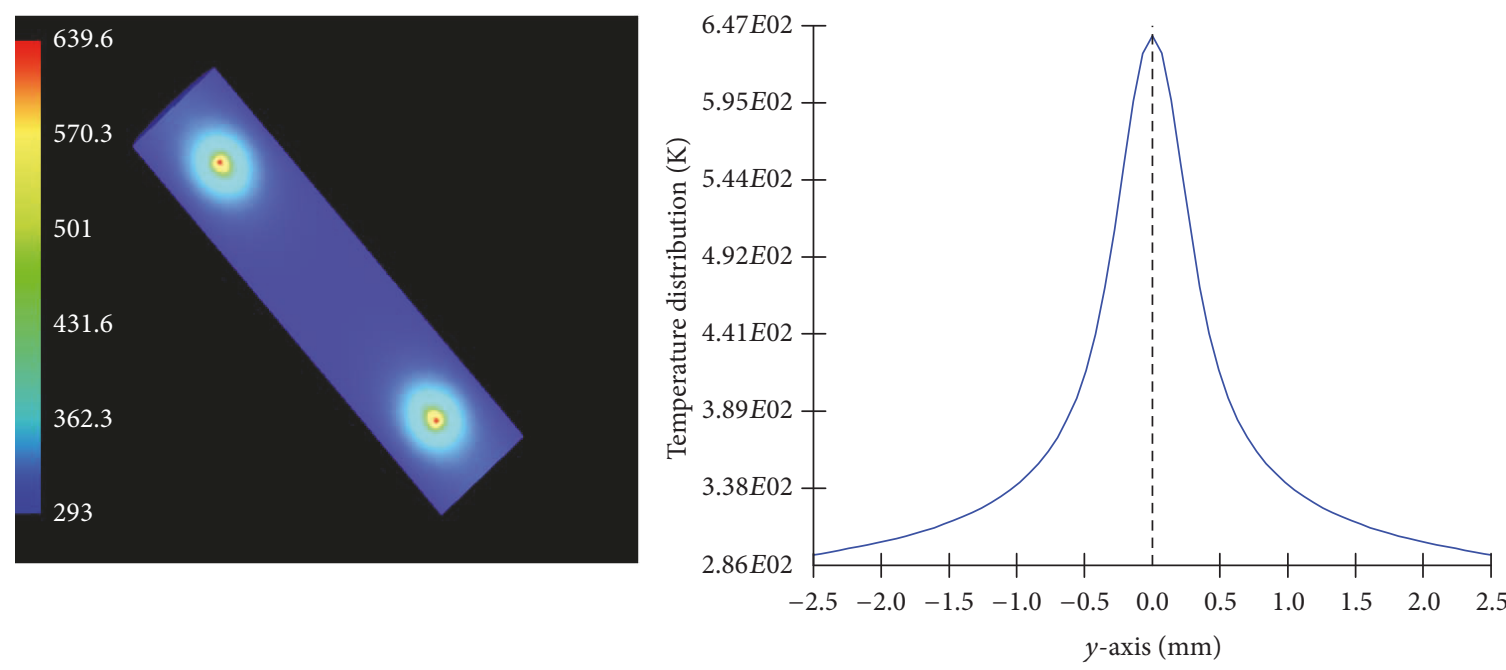

, FEM data

(b)

Figure 14: Composite material Nd:KGW: (a) $15 \mathrm{~mm}$, radius $r=3 \mathrm{~mm}$, with $3 \mathrm{~mm}$ undoped caps at both ends, single pumped; (b) $15 \mathrm{~mm}$, radius $r=3 \mathrm{~mm}$, with $3 \mathrm{~mm}$ undoped caps at both ends, dual pumped.

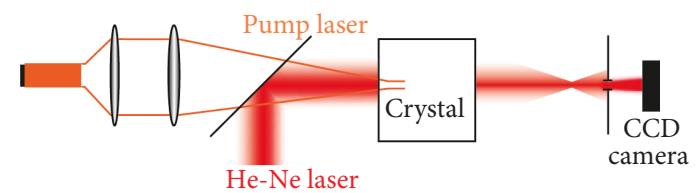

FIGURE 15: Thermal lens measurement based on the displacement of the focal point.

thermal lensing, which makes it a perfect tool to aid in designing and implementing solid-state lasers. We note the following:

(i) In all cases studied, a thermal lensing effect was visible and it ought to be taken into consideration in all types of DPSS lasers. (ii) Using a composite crystal reduced thermal and stress effects to less than $10 \%$ in all cases studied except for the case of Nd:KGW where the maximum temperature was less by about $30 \%$ when the composite crystal is used; this is due to the short absorption path in this material which concentrates temperature over a relatively short distance and thus increases dissipation effects of undoped caps.

(iii) Nd:KGW crystals are suitable to build high power diode end-pumped solid-state lasers; because of the short absorption length in Nd:KGW, we can build a short resonator. However, adding caps to the composite KGW rod reduced thermal effects and could improve performance. 
TABLE 4: Thermal focal length calculated using FEA.

\begin{tabular}{|c|c|c|c|c|c|c|}
\hline & \multirow{2}{*}{ Crystal } & \multirow{2}{*}{$\begin{array}{c}\text { Length } \\
(\mathrm{mm})\end{array}$} & \multirow{2}{*}{$\begin{array}{c}\text { Diameter } \\
(\mathrm{mm})\end{array}$} & \multicolumn{3}{|c|}{ Focal length of thermal lens (mm) } \\
\hline & & & & $10 \mathrm{~W}$ & $15 \mathrm{~W}$ & $20 \mathrm{~W}$ \\
\hline 1 & Nd:YAG & 10 & 3 & 118 & 79 & 58 \\
\hline 2 & Nd:YAG & 10 & 5 & 118 & 78 & 58 \\
\hline 3 & Nd:YAG & 15 & 3 & 115 & 76 & 56 \\
\hline 4 & Nd:YAG & 15 & 5 & 115 & 76 & 56 \\
\hline 5 & Nd:KGW & 15 & 5 & 53 & 33 & 23 \\
\hline 6 & Nd:KGW & 15 & 3 & 53 & 32 & 23 \\
\hline 7 & Yb:YAG & 15 & 5 & 499 & 332 & 248 \\
\hline 8 & Yb:YAG & 15 & 3 & 500 & 332 & 248 \\
\hline 9 & Nd:YAG dual pump & 15 & 5 & 58 & - & - \\
\hline 10 & $\mathrm{Nd}: K G W$ dual pump & 15 & 5 & 28 & - & - \\
\hline 11 & Yb:YAG dual pump & 15 & 5 & 251 & - & - \\
\hline 12 & Nd:YAG composite & 15 & 5 & 240 & - & - \\
\hline 13 & Nd:KGW composite & 15 & 5 & 1086 & - & - \\
\hline 14 & Yb:YAG composite & 15 & 5 & 1032 & - & - \\
\hline
\end{tabular}

(iv) From the comparison with the experiment, we found that thermal focal length predicted from FEA is about $10 \%$ less than measured values, which should be taken into account in designing diode pumped solid-state lasers; this issue can be studied further using suitable analytical models.

In conclusion, we find that heat effects play a major role in diode pumped solid-state lasers and should be taken into account in laser design. To overcome the undesired thermal effects in laser crystals, we need to develop accurate methods to measure thermal lensing, mathematical models to predict thermal effects accurately $[11,12]$, and various compensation techniques to reduce the effects of thermal lensing [13-16].

\section{Conflicts of Interest}

The author declares that there are no conflicts of interest regarding the publication of this paper.

\section{References}

[1] M. Sovizi and R. Massudi, "Thermal distribution calculation in diode pumped Nd:YAG laser rod by boundary element method," Optics and Laser Technology, vol. 39, no. 1, pp. 46-52, 2007.

[2] K.-F. Tseng and Y.-S. Huang, "The optimum characteristics for the fiber coupled laser diode end-pumped lasers," Journal of Chung Cheng Institute of Technology, vol. 34, no. 2, pp. 47-56, 2006.

[3] Y. F. Chen, T. S. Liao, C. F. Kao, T. M. Huang, K. H. Lin, and S. C. Wang, "Optimization of fiber-coupled laser-diode end-pumped lasers: influence of pump-beam quality," IEEE Journal of Quantum Electronics, vol. 32, no. 11, pp. 2010-2016, 1996.

[4] W. Koechner, Solid-State Laser Engineering, Springer Series in Optical Sciences, Springer, London, UK, 6th edition, 2006.

[5] Z. Zhuo, T. Li, X. Li, and H. Yang, "Investigation of Nd: $\mathrm{YVO}_{4} /$ $\mathrm{YVO}_{4}$ composite crystal and its laser performance pumped by a fiber coupled diode laser," Optics Communications, vol. 274, no. 1, pp. 176-181, 2007.

[6] E. Safari and A. Kachanov, "Estimation of thermal lensing effect in the high-power end-pumped direct-cut crystal lasers," Optics and Laser Technology, vol. 38, no. 7, pp. 534-539, 2006.

[7] S. Chénais, F. Druon, S. Forget, F. Balembois, and P. Georges, "On thermal effects in solid-state lasers: the case of ytterbiumdoped materials," Progress in Quantum Electronics, vol. 30, no. 4, pp. 89-153, 2006.

[8] Y.-S. Huang, H.-L. Tsai, and F.-L. Chang, "Thermo-optic effects affecting the high pump power end pumped solid state lasers: modeling and analysis," Optics Communications, vol. 273, no. 2, pp. 515-525, 2007.

[9] LAS-CAD GmbH, Munich, Germany, http://www.las-cad.com/.

[10] K. Altmann, C. Pflaum, and D. Seider, "Semi-unstructured grids in the laser simulation program LASCAD," Proceedings in Applied Mathematics and Mechanics, vol. 2, no. 1, pp. 438-439, 2003.

[11] A. Dement'ev, A. Jovai, K. R. Ckaitis, F. Ivanauskas, and J. D. Bagdonaviciene, "Numerical treatment of the temperature distribution in end-pumped composite laser rods," Lithuanian Journal of Physics, vol. 47, no. 3, pp. 279-288, 2007.

[12] S. Fan, X. Zhang, Q. Wang, S. Li, S. Ding, and F. Su, "More precise determination of thermal lens focal length for endpumped solid-state lasers," Optics Communications, vol. 266, no. 2, pp. 620-626, 2006.

[13] R. Hua, S. Wada, and H. Tashiro, "Analytical method for design a $\mathrm{TEM}_{00}$ mode resonator of a dual-rod Nd:YAG laser with full birefringence compensation," Optics Communications, vol. 232, no. 1-6, pp. 333-341, 2004.

[14] I. Moshe and S. Jackel, "Correction of thermally induced birefringence in double-rod laser resonators-comparison of various methods," Optics Communications, vol. 214, no. 1-6, pp. 315325,2002 .

[15] M. Frede, R. Wilhelm, M. Brendel et al., "High power fundamental mode Nd:YAG laser with efficient birefringence compensation," Optics Express, vol. 12, no. 15, pp. 3581-3589, 2004. 
[16] R. Koch, "Self-adaptive optical elements for compensation of thermal lensing effects in diode end-pumped solid state lasersproposal and preliminary experiments," Optics Communications, vol. 140, no. 1-3, pp. 158-164, 1997. 


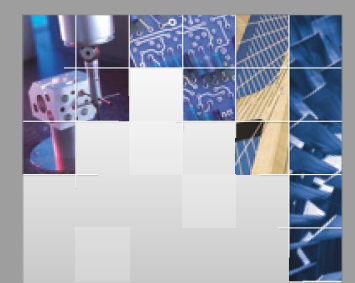

\section{Enfincering}
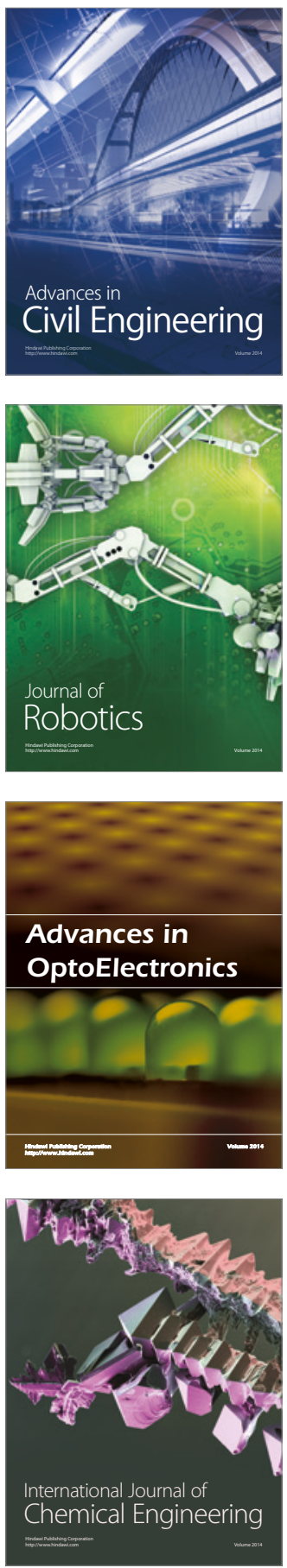

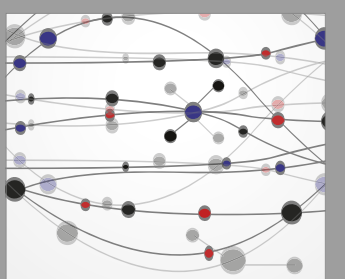

The Scientific World Journal

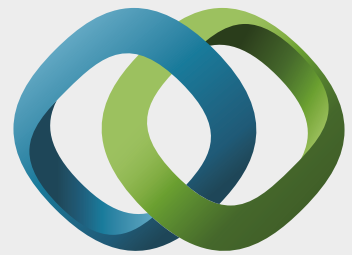

\section{Hindawi}

Submit your manuscripts at

https://www.hindawi.com
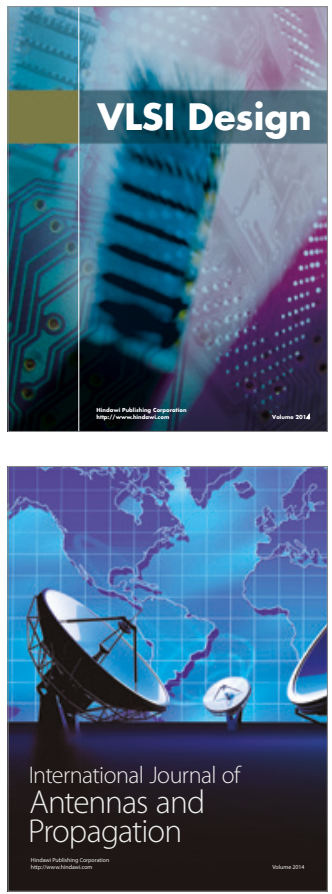

\section{Rotating}

Machinery
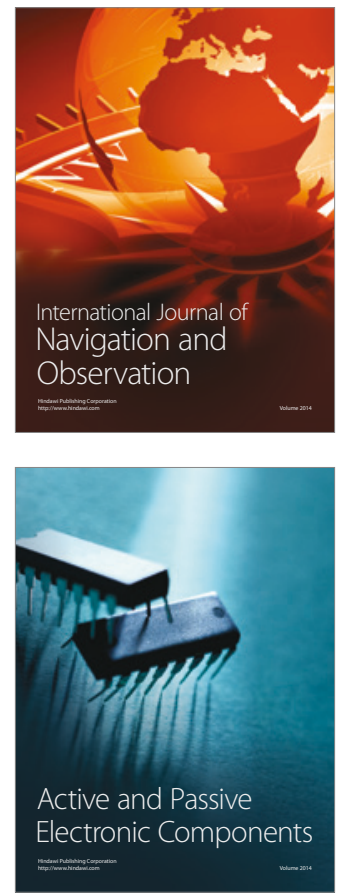
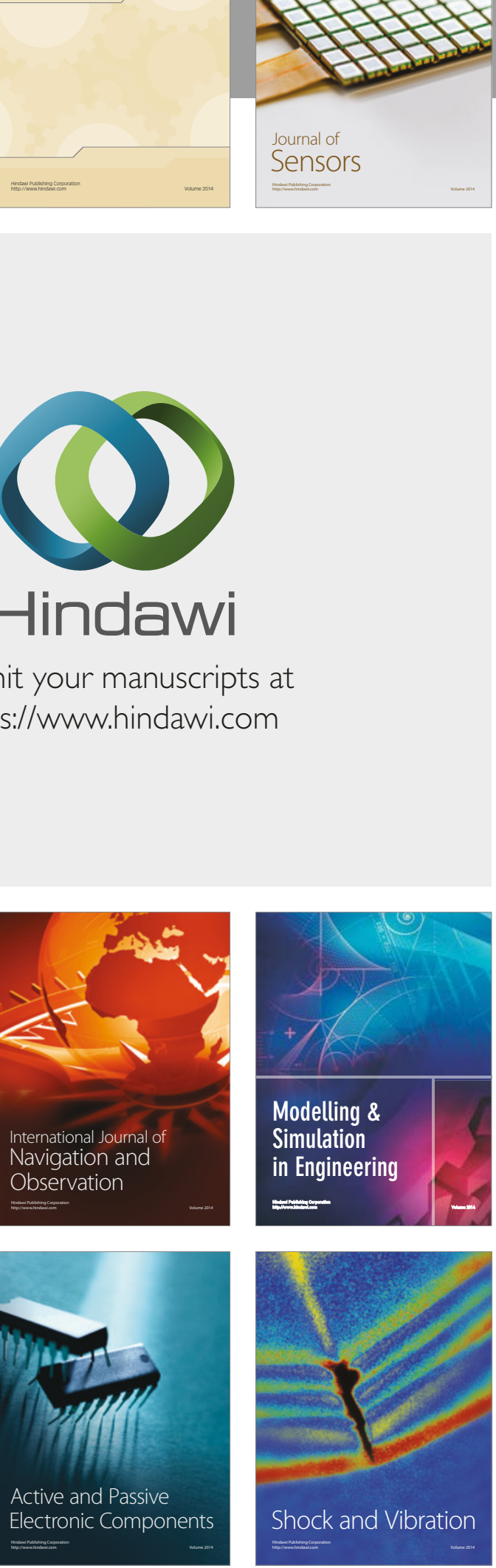
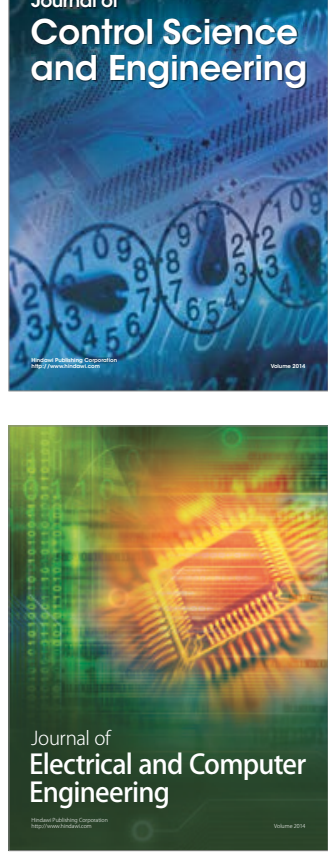

Distributed

Journal of

Control Science

and Engineering
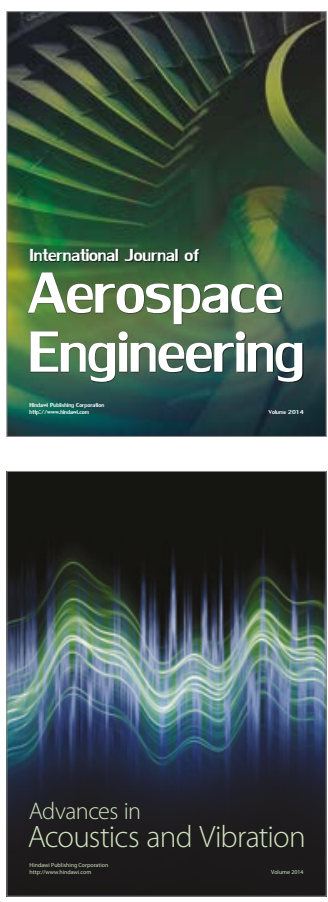

Sensor Networks 